Research Article

\title{
Stability and Failure Mechanism Analyses of the Zhenggang Landslide in Southwestern China
}

\author{
Shengnian Wang $D^{D},{ }^{1}$ Weiya $\mathrm{Xu}^{2}$ and Jinyuan $\mathrm{Liu}^{3}$ \\ ${ }^{1}$ College of Transportation Science \& Engineering, Nanjing Tech University, Nanjing 211800, China \\ ${ }^{2}$ Institute of Geotechnical Engineering, Hohai University, Nanjing 210098, China \\ ${ }^{3}$ Department of Civil Engineering, Ryerson University, Toronto, ON, Canada M5B 2K3 \\ Correspondence should be addressed to Shengnian Wang; shengnian.wang@foxmail.com
}

Received 22 August 2017; Revised 27 December 2017; Accepted 15 January 2018; Published 20 March 2018

Academic Editor: Giovanni Garcea

Copyright (c) 2018 Shengnian Wang et al. This is an open access article distributed under the Creative Commons Attribution License, which permits unrestricted use, distribution, and reproduction in any medium, provided the original work is properly cited.

\begin{abstract}
The Zhenggang landslide is an ancient complex landslide located at southeastern Tibetan Plateau, China. Due to intensive rainfalls in 2008 and heavy snowfalls in 2009, the Zhenggang landslide exhibited a high probability of reactivation once again. In this study, geological structure, matter features, and macrodeformations of the Zhenggang landslide (including Zone I and Zone II) were investigated for uncovering its formation mechanism and evolution tendency first, and then the stability and failure mechanism analyses of the Zhenggang landslide were conducted in detail by a combined limit equilibrium and finite element analysis method. Results of geological investigations indicate that the Zhenggang landslide has undergone sliding several times and is in a metastable state now. The distribution of the activity of the landslide is a retrogressive landslide in Zone I but an advancing landslide in Zone II. Such conclusions are further proved by the numerical stability and failure analyses.
\end{abstract}

\section{Introduction}

Uplift of tectonically active mountain belts, such as Himalayas (also known as Tibetan Plateau in China), Southern Alps of New Zealand, and Andes, generates high topographic relief and incised river gorges, resulting in not only abundant potential hydroelectric resources but also sufficient gravitational potential for landslides to occur [1]. Landslides thus have been one of the most destructive nature hazards, especially large-scale landslides in mountainous areas [2-4]. Causes of landslides in mountainous areas indicate that the occurrence of landslides should be a result of complex hydromechanical process related to geomaterial properties, hydrogeological conditions, earthquakes, and rainfalls [5-11]. However, due to the frequency and adequacy of rainstorms, rainfall-induced landslides are one of the major geological hazards at present $[12,13]$, especially when landslides occur in coarse-grained soils [14-16]. Some studies pointed out that intense short-duration rainfalls always cause surface erosions or shallow landslides in a homogeneous slope, while preexisting surface cracks or weak interlayered clays are much more easily triggering a deep-seated landslide failure during prolonged rainfalls [17]. Such difference is chiefly because potential sliding surfaces related to preexisting cracks on ground surface are prone to concentrated water infiltration, leading to positive water pressure overlying the interlayered clays or bedrock interfaces during or after rainfalls [18-20]. At the same time, the water that exists in the landslide continuously softens the effective strength of the soil, resulting in large deformation and long-distance rapid movement.

The Zhenggang landslide $\left(\mathrm{E} 98^{\circ} 55^{\prime}-98^{\circ} 90^{\prime}, \mathrm{N} 28^{\circ} 30^{\prime}-28^{\circ} 40^{\prime}\right)$ is a huge ancient landslide located at the right bank of the downstream of the Gushui hydropower station in the southeastern Tibetan Plateau of China (Figure 1) and has a serious impact on the safety of diversion tunnels and flood discharge tunnels of the hydropower station. Unfortunately, due to the intensive rainfalls in October 2008 and the heavy snowfalls in February 2009, the Zhenggang landslide exhibited large deformations along an interlayered clay once again. The instability analysis of the landslide is thus highly urgent to dam construction. In this study, the formation mechanism and evolution tendency of the Zhenggang landslide will be analyzed 


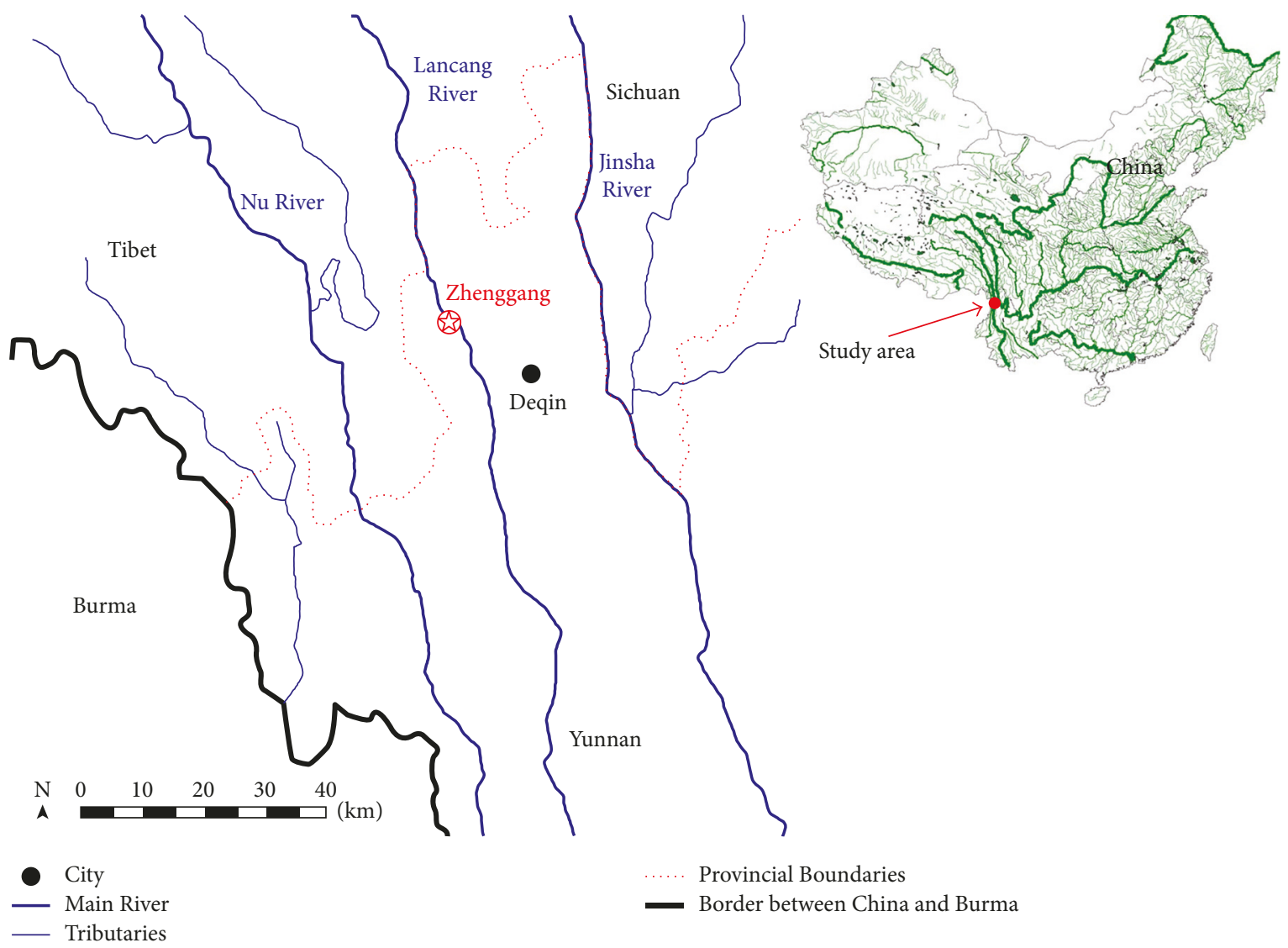

Figure 1: Site location of the Zhenggang landslide.

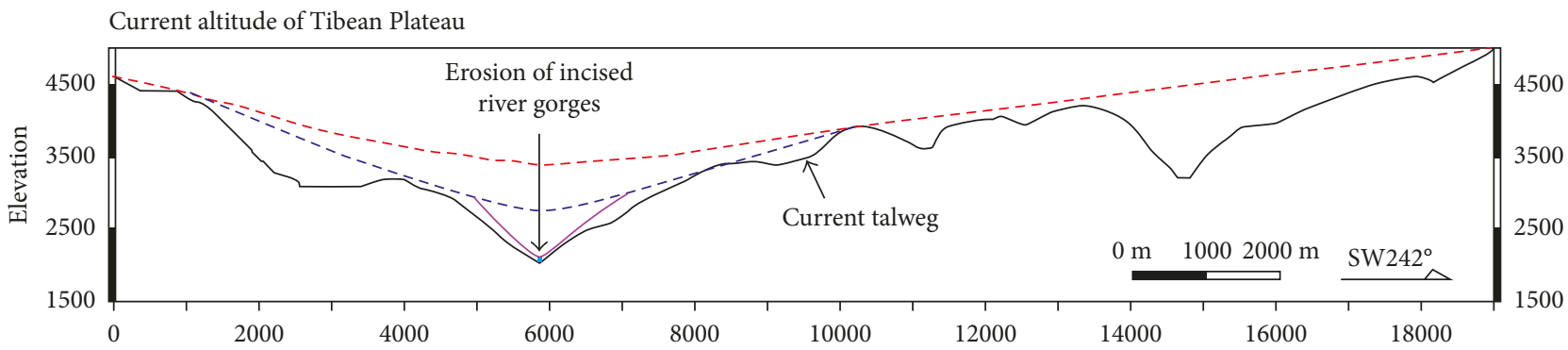

Figure 2: Typical terrain profile of the river valleys.

first. Then the stability and deformation features of the Zhenggang landslide will be studied by a combined limit equilibrium and finite element analysis method. Finally, a comprehensive treatment scheme will be discussed.

\section{Regional Setting of the Zhenggang Landslide}

2.1. Regional Topographic and Geomorphic Conditions. Due to the uplift of the Tibetan Plateau caused by India-Asia collision, the regional geological structures of the Zhenggang area are subjected to a strong extrusion activity. Three parallel rivers are an outstanding representative reminder of the major stages and incidents in the evolution history of this zone, as shown in Figure 1. The regional geomorphic attributes near the Zhenggang landslide are high mountains and deep valleys, with the north side higher than the south. The main direction of mountains is NNW and nearly SN. The Lancang River flows from north to south. The shape of incised river valleys turns on a " $\mathrm{V}$ " (Figure 2). The natural slope of both sides of the river is $20^{\circ}-45^{\circ}$. River terraces are developed. Figure 3(a) shows that the external boundary of the Zhenggang landslide shows a tongue shape on a plane, and the crown of the whole landslide takes on a shape of a round-backed armchair. Three main gullies: Upstream gully, Zhenggang gully, and Yagong gully scatter on the ground surface. The Zhenggang gully suffered from the most intensive gully erosion, leading to the deepest terrain incision depth. So the whole landslide in geomorphologic structure can be divided into two subdomains: Zone I and Zone II. Geological survey and field reconnaissance indicate 


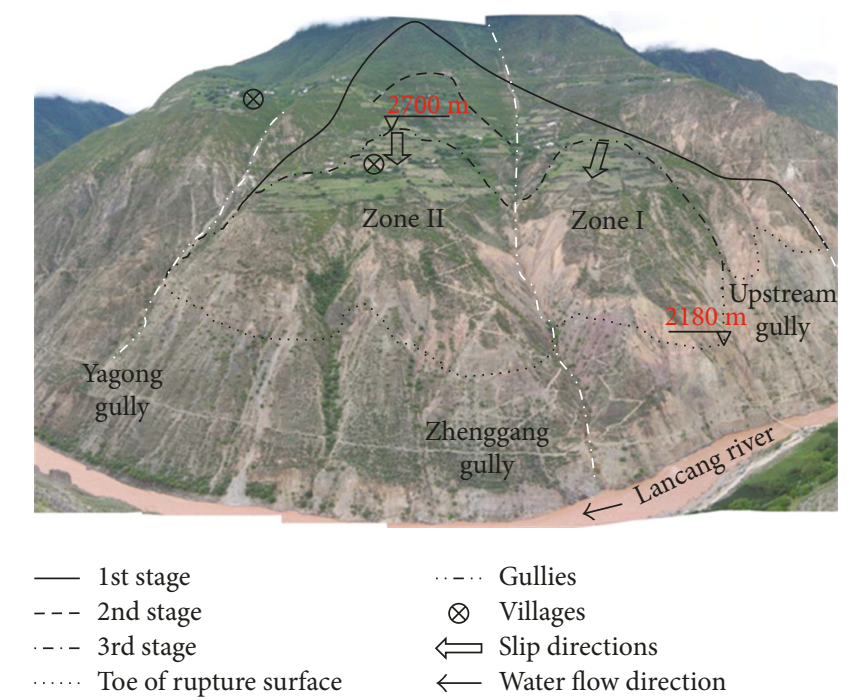

(a)

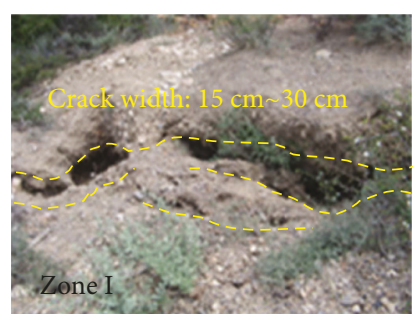

(b)

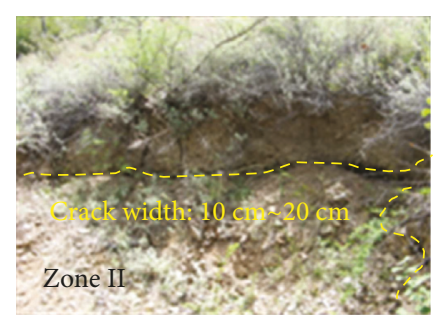

(c)

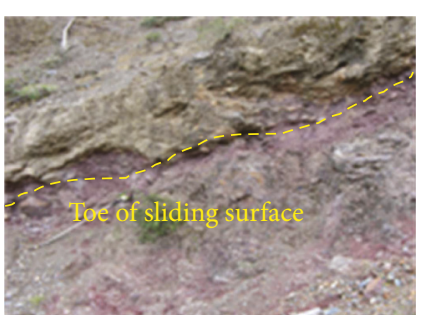

(d)

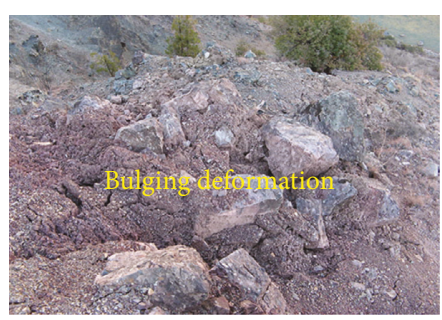

(e)

FIgURE 3: The topographic and geomorphic features of the Zhenggang landslide.

that the slope of the landslide is about $30^{\circ}-50^{\circ}$ above the elevation of $2750 \mathrm{~m}$, about $20^{\circ}-30^{\circ}$ between the elevation of $2250 \mathrm{~m}$ to $2750 \mathrm{~m}$, and about $40^{\circ}$ below the elevation of $2250 \mathrm{~m}$. Above the elevation of $2250 \mathrm{~m}$, the topographic integrity is good and the aboveground vegetation is relatively developed. Below the elevation of $2250 \mathrm{~m}$, the topographic integrity is poor and the retrogressive gully erosion is developed. Below the elevation of $2100 \mathrm{~m}$, the bedrock of partial sections along both banks of the river is exposed. The upstream boundary of the landslide deposit extends mainly along $\mathrm{S} 5^{\circ}-20^{\circ} \mathrm{W}$ above the elevation of $2450 \mathrm{~m}, \mathrm{~S} 65^{\circ} \mathrm{W}$ with an elevation of $2250-2450 \mathrm{~m}$, and SN below the elevation of $2250 \mathrm{~m}$. The geomaterials at the upstream boundary of the landslide deposit are mainly clastic rock and glacial stony soil with thickness ranging from $5 \mathrm{~m}$ to $20 \mathrm{~m}$. The lithology of the clastic rock is weakly weathered basalt with a typical layering structure and rhythmic texture. The downstream boundary of the landslide deposit extends mainly along $\mathrm{S} 60^{\circ} \mathrm{W}$ with an elevation of $2200-2500 \mathrm{~m}$ but gradually deviates from the Yagong gully to the upstream region above the elevation of $2500 \mathrm{~m}$. At present, it can be clearly seen that the landslide deposit is obviously separated from the sliding bed. Below the sliding bed, the bedrock is exposed. The geomaterials at the downstream boundary of the landslide deposit are quaternary deposits, including residual slope sediments, glaciofluvial deposits, and collapse deposits. The depth of the geomaterials is ranging from $10 \mathrm{~m}$ to $20 \mathrm{~m}$. The lithology of the underlying bedrock is sandstone and slate.
Below the elevation of $2200 \mathrm{~m}$, the landslide deposit layer formed from limestone sliding is visible in local. The limestone is strong weathered and has an exposed width of about 2-3 $\mathrm{m}$. Moreover, two-tensional depression zones parallel to the crown of the landslide had emerged in the elevations of 2800-2900 m and 2500-2700 m, which formed obvious scarps. The average depth of the tensional depression zones is about $2 \mathrm{~m}$ with the maximum depth of $5 \mathrm{~m}$. The region near the toe of sliding surface turns on an obvious bulging deformation within the elevation ranging from $2180 \mathrm{~m}$ to $2210 \mathrm{~m}$, as shown in Figures 3(b)-3(e).

2.2. Engineering Geology and Hydrogeological Conditions. Figure 4(a) shows that the landslide has an elevation of 2180 $3220 \mathrm{~m}$, with a maximum valley width about $1300 \mathrm{~m}$. The area of the landslide is 1.7 million $\cdot \mathrm{m}^{2}$. The volume of the landslide is approximately $47.2 \mathrm{million} \cdot \mathrm{m}^{3}$ (including 9.4 million $\cdot \mathrm{m}^{3}$ in the Zone I and 38.1 million $\cdot \mathrm{m}^{3}$ in the Zone II). Results of geological survey indicates that all kinds of rock outcrops, including magmatic, sedimentary, and metamorphic rocks, are visible in this area, as shown in Figure 4(c). The normal tectonic formation under the landslide deposit is a monocline structure with the occurrence of $\mathrm{N} 20^{\circ}-30^{\circ}$, SW $\angle 65^{\circ}-85^{\circ}$. Due to strong bending and toppling deformation, the occurrence of the topping rock masses near the landslide deposit is $\mathrm{N} 30^{\circ}-35^{\circ}, \mathrm{SW} \angle 15^{\circ}-30^{\circ}$. Compressive structural surfaces are developed so that the stratigraphic 


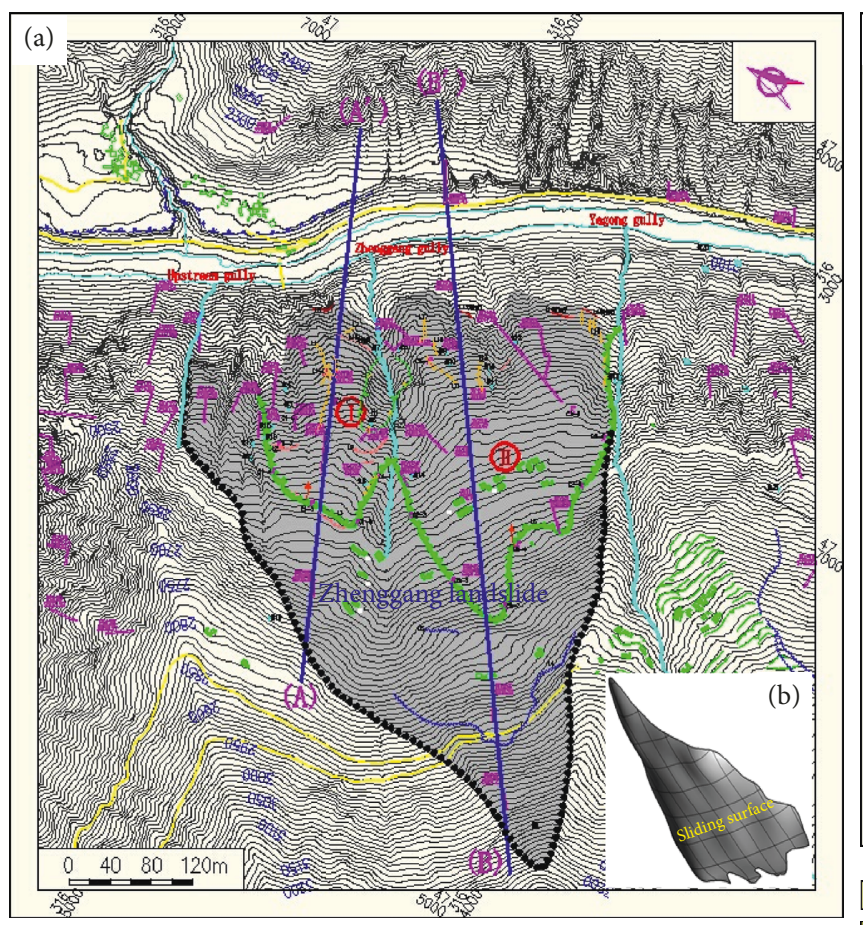

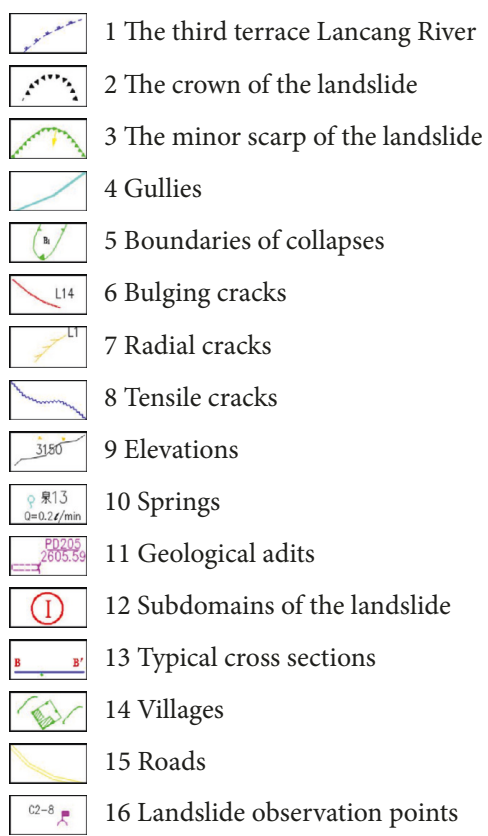

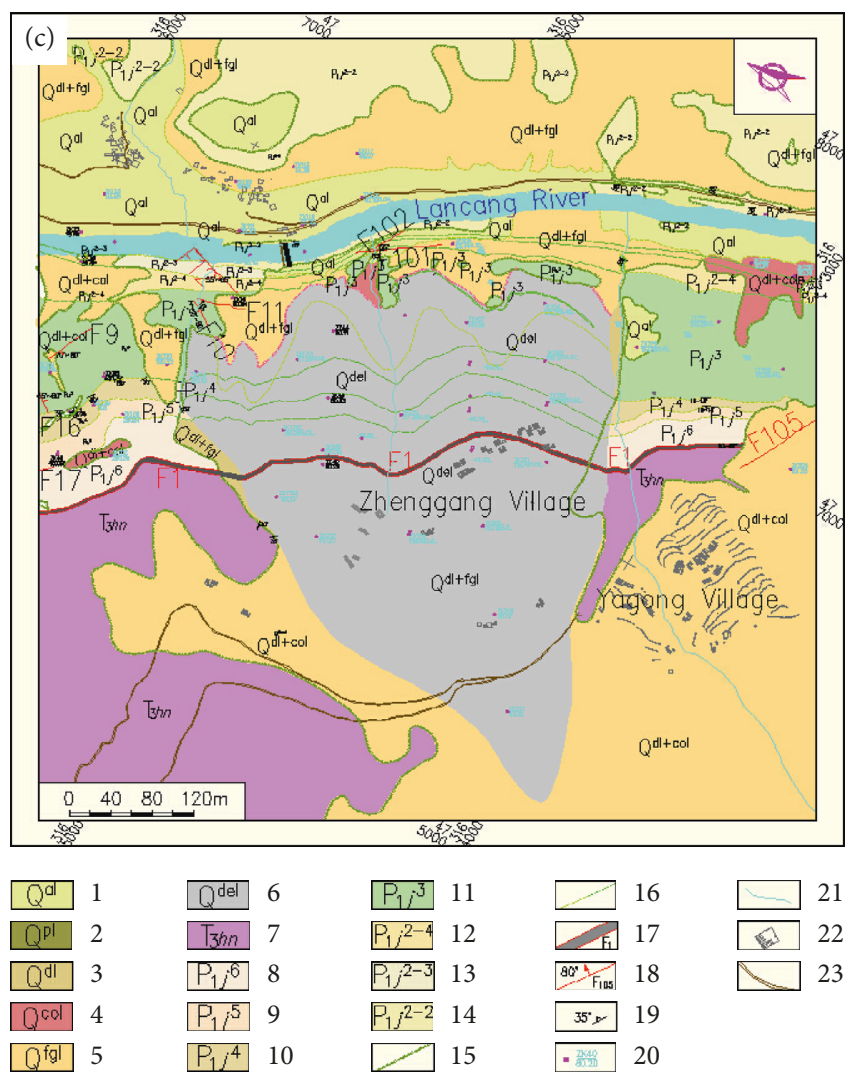

1 Alluvial deposit of holocene series

2 Proluvial deposits of holocene series

3 Diluvial deposits of holocene series

4 Colluvial deposits of holocene series

5 Glacial deposits of holocene series

6 Landslide deposit

7 Hongpo formation of upper triassic

8-14 Donglong formation of lower permian

15 Boundary of sediments and bedrocks

16 Deduced boundary of rock formations

17 Hongshan-Gushui fault

18 Other faults

19 Occurrence of metamorphic rocks

20 Boreholes

21 Gullies

22 Villages

23 Roads

Figure 4: The engineering geological map of the Zhenggang landslide.

contact relationships are given priority to tectonic faults in this area. Results of borehole show that the sliding surface of the landslide developed mainly along an interlayered clay. It is inward sunken overall but slightly doming at some places inside. The shape of the whole sliding surface approximately takes on a spoon shape, as shown as in Figure 4(b). The occurrence of the sliding surface is $\mathrm{N} 30^{\circ}-50^{\circ} \mathrm{W}, \mathrm{NE} \angle 40^{\circ}-60^{\circ}$ at the top part, $\mathrm{N} 30^{\circ}-40^{\circ} \mathrm{W}, \mathrm{NE} \angle 20^{\circ}-40^{\circ}$ at the middle part, and $\mathrm{N} 30^{\circ}-40^{\circ} \mathrm{W}, \mathrm{NE} \angle 10^{\circ}-20^{\circ}$ at the toe part. The results of the borehole also indicated that the Zhenggang landslide formed relatively early and had experienced several times of large sliding in the past. Therefore, the landslide shall be a multistage complex landslide.

Figure 5 indicates that there are mainly three layers of materials from top to bottom, including landslide deposit, interlayered clay (henceforth referred to as slip zone), and bedrocks. The landslide deposit mainly consists of Quaternary sediments, including diluvium layer of Quaternary System $\left(Q^{\mathrm{dl}}\right)$, glaciofluvial deposit of Holocene Series $\left(Q^{\mathrm{fgl}}\right)$, and landslide deposit $\left(Q^{\mathrm{del}}\right)$. Resluts from borehole exploration (all of them exposed the layer of the landslide deposit) show that the thickness of the landslide deposit in Zone I is about 


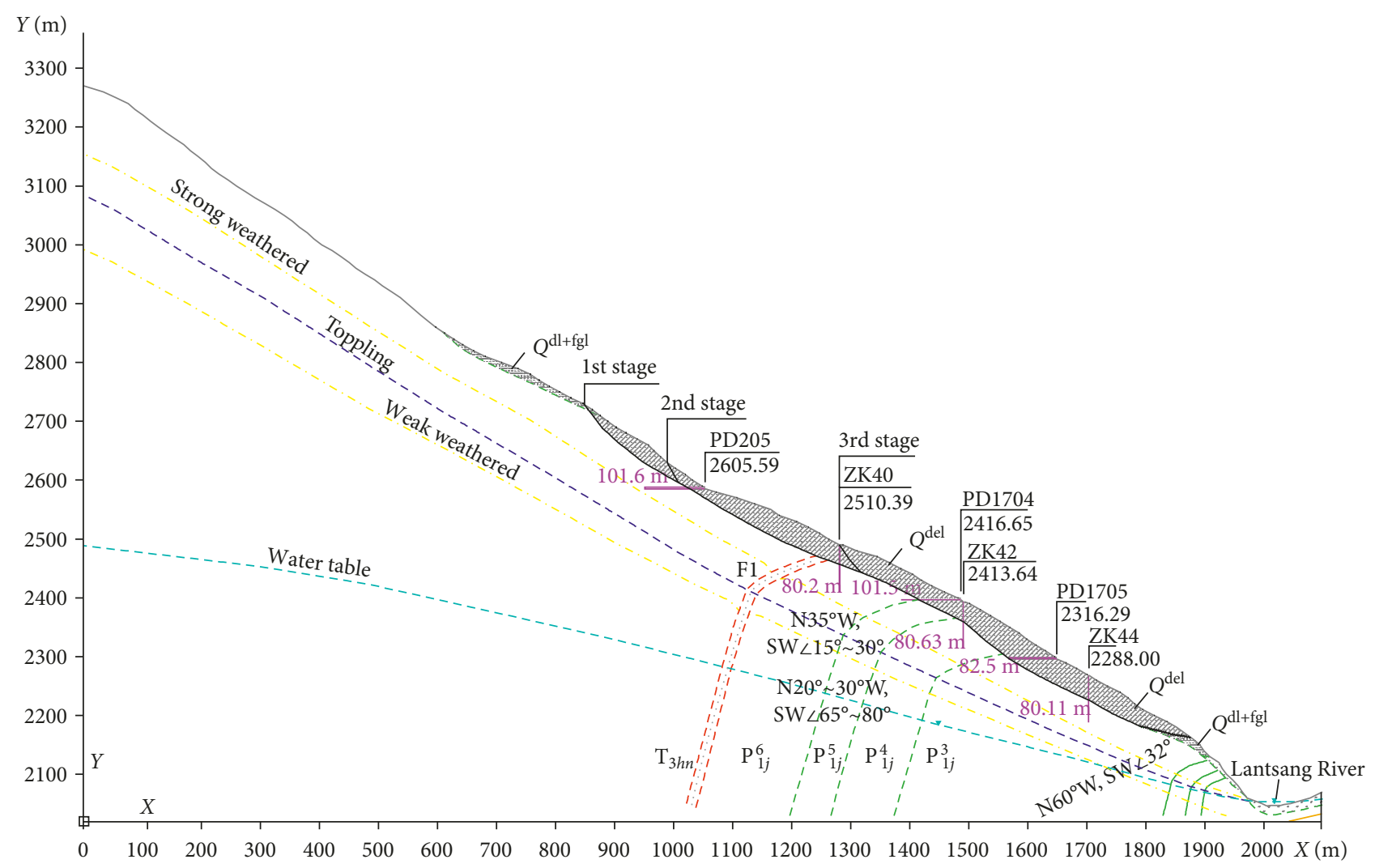

(a)

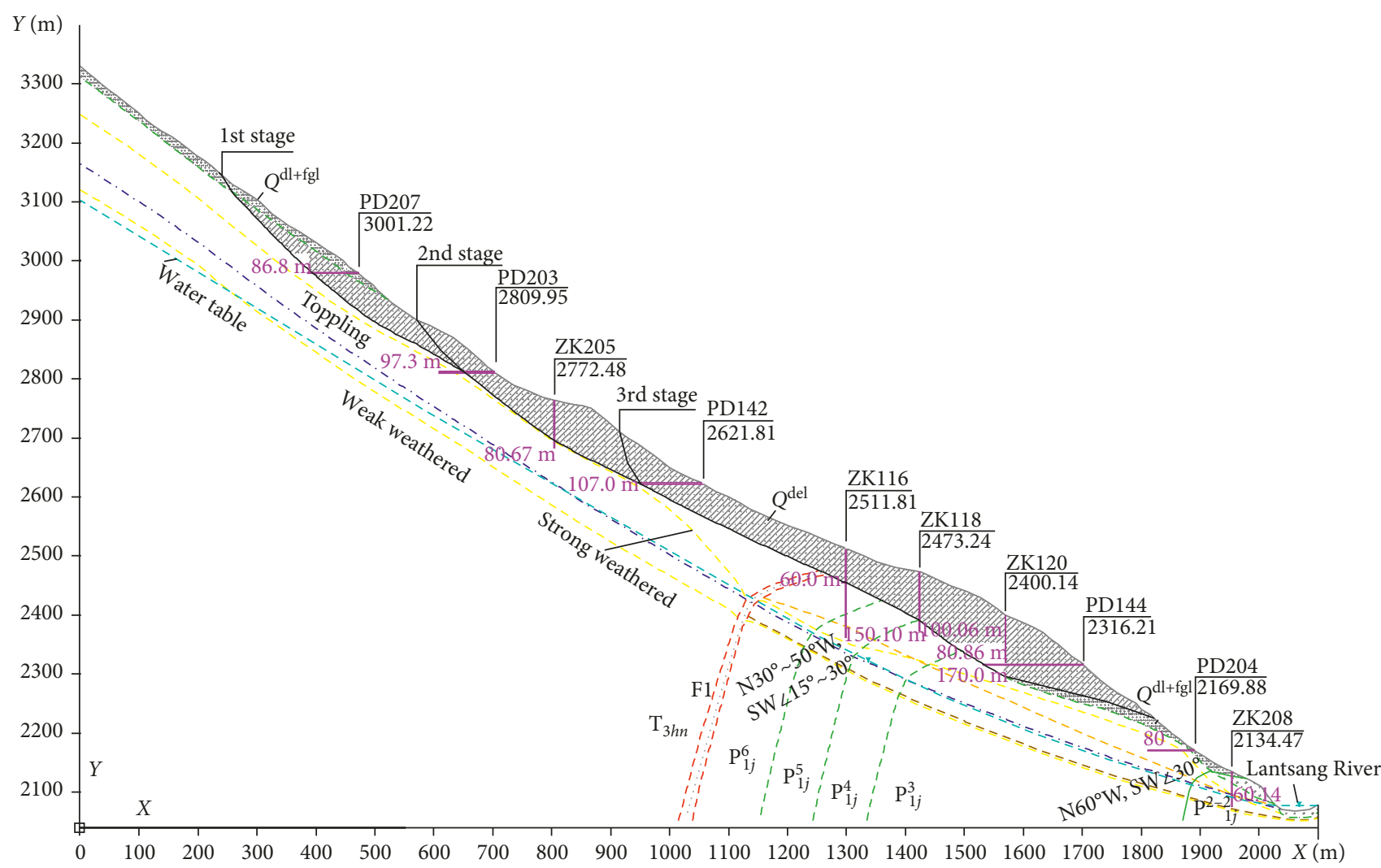

(b)

Figure 5: Typical profiles of the Zhenggang landslide: (a) $A-A^{\prime}$ in Zone I; (b) B- $\mathrm{B}^{\prime}$ in Zone II. 
20-30 m below the elevation of $2300 \mathrm{~m}$ (e.g., ZK44), about $30-40 \mathrm{~m}$ between the elevation of 2250 to $2750 \mathrm{~m}$ (e.g., ZK40 and ZK42), and about 20-30 $\mathrm{m}$ above the elevation of $2600 \mathrm{~m}$; the thickness of the landslide deposit in Zone II is about $30-50 \mathrm{~m}$ below the elevation of $2300 \mathrm{~m}$ (e.g., ZK208), about $50-100 \mathrm{~m}$ between the elevation of 2300 to $2500 \mathrm{~m}$ (e.g., ZK118 and ZK120), and about 30-40 $\mathrm{m}$ above the elevation of $2500 \mathrm{~m}$ (e.g., ZK116 and ZK205). The thickness of the landslide deposit near the Zhenggang gully and other small gullies is relatively thin. Results from exploratory adits show that the thickness of the landslide deposit in Zone I is about 20-30 m below the elevation of $2300 \mathrm{~m}$, about $80-90 \mathrm{~m}$ between the elevation of 2300 to $2600 \mathrm{~m}$ (e.g., PD1704 and PD1705), and about 30-40 $\mathrm{m}$ above the elevation of $2600 \mathrm{~m}$ (e.g., PD205); the thickness of the landslide deposit in Zone II is about $40-60 \mathrm{~m}$ below the elevation of $2300 \mathrm{~m}$ (e.g., PD204), about $120-170 \mathrm{~m}$ between the elevation of 2300 to $2500 \mathrm{~m}$ (e.g., PD144, it exposed the bottom boundary of the landslide in the depth of $168.20 \mathrm{~m}$ ), and about $30-40 \mathrm{~m}$ above the elevation of $2500 \mathrm{~m}$ (e.g., PD142, PD203, and PD207). Results from both borehole exploration and exploratory adits show that the materials of the landslide deposit are composed by fine sandy soil and lumps of weathered basalt gravels ranging in size from a few centimeters to more than $20 \mathrm{~m}$. The cementation is weak. The features of rhythm structure are obvious with an occurrence of $N 5^{\circ} \mathrm{W}, \mathrm{NE} \angle 30^{\circ}-40^{\circ}$. Due to the loose structure and high permeability of the landslide deposit, melting water and atmospheric precipitation can infiltrate into the landslide deposit rapidly. The landslide deposit bulges obviously near the toe of the sliding surface and has been subjected to disintegration many times.

The slip zone is a thin layer of fine-grained material between the bottom of the landslide deposit and the underlying bedrock (or toppling deformation rock mass), as shown in Figures 6(a)-6(c). Results from both borehole exploration and exploratory adits show that the occurrence of the slip zone is $\mathrm{N} 30^{\circ}-50^{\circ} \mathrm{W}, \mathrm{NE} \angle 40^{\circ}-60^{\circ}$ at the top part, $\mathrm{N} 30^{\circ}-40^{\circ} \mathrm{W}, \mathrm{NE} \angle 20^{\circ}-40^{\circ}$ at the middle part, and $\mathrm{N} 30^{\circ}-40^{\circ} \mathrm{W}$, $\mathrm{NE} \angle 10^{\circ}-20^{\circ}$ at the toe part. The thickness of slip zones, exposed at exploratory adits, is approximately $20-200 \mathrm{~cm}$. The materials of them as a whole are clayey and compacted wet fine soils, mixed with 10-30\% small rock fragments that have well psephicity and range in sizes from 1 to $3 \mathrm{~cm}$. The phenomena of shearing slip, specifically in some local areas, are visible as shown in Figure 6(d). The material composition of the slip zone is different in different parts. The material in a dry state at the top part has a high content of rock fragments, the lithology of which is slate and sandstone. The material in a plastic state at the middle part has a high content of clayey soil. The mingled rock fragments at the middle part are mainly composed of slate and sandstone, but with a small amount of limestone and mudstone. The material at the toe part has a high content of rock fragments, the lithology of which is slate, sandstone, limestone, and basalt. Therefore, the slip zone has a high shear strength at the top and toe part but a relatively low shear strength in the middle part. Results disclosed at exploratory adit (PD204) indicate that the bedrock underlying the toe of the landslide deposit is the Lower Permian celadon basalts $\left(\mathrm{P}_{1 j}^{3}\right)$ (Figure $6(\mathrm{e})$ ) and the metamorphic sandstone
$\left(\mathrm{T}_{3 h n}\right)$ (Figure 6(f)). They are strongly unloading and rebound toppling rock masses and are very fractured and weathered. The shear and tensile fractures orienting downward slope are developed and have the characteristics of intensive and equalinterval distributions. The rock mass takes on special blocklayered structure. The average spacing of opening fracture distributions is approximately $20-40 \mathrm{~cm}$. No filling material or only little amount of small rock debris are in opening fractures. The overhead phenomenon of rock mass is obvious. The hammering sound on adit's wall is stuffy. Compared with the other results of exploratory adits basically at the same elevation, the depths of strongly unloading and rebound zones are obviously deepened, which indicate that the landslide thrust coming from the sliding body leads to the shear breaking and the structure disintegration of basalt.

The hydrogeological conditions around the Zhenggang area are simple. The groundwater is mainly fissure water flowing in rock fractures. Since the joints of the rock mass are well developed due to serious unloading, rebound, and stress relief of bedrocks, the permeability of the rock mass is relatively higher than the slip zone. However, since the groundwater table is normally lower than the slip zone, the influence of groundwater on the landslide stability is not considered in this study.

\subsection{Deformation History and Evolution Tendency of the} Landslide. The geological survey indicates that the tectonic deformation system in the landslide area is controlled mainly by the dextral shear between India Plate and Asia Plate. Geostatic stress, disadvantage structure surface, and unloading deformation are the controlling factors for the landslide deformation and evolution. Glaciation, groundwater, and earthquake are inducements for the landslide instability and failure. Results of borehole exploration (e.g., ZK44 and ZK208) and exploratory adits (e.g., PD204 and PD144) indicate that the limestone belt distributed at the toe of landslide deposit is belonging to the residual deposits of $\mathrm{P}_{1 j}^{5}$ rock formation, which also is exposed at the flank of the Zhenggang landslide. Therefore, it can be concluded that the sliding distance of the landslide sliding towards to the Lancang River has reached to $400-500 \mathrm{~m}$. The geological survey also disclosed the stratigraphic contact relationship of the Zhenggang area, as shown in Figure 7. The glacial deposit was formed later than the formation of the third terrace. The formation of the old landslide was formed later than the glacial period. So the evolution process of the Zhenggang landslide can be divided into three dynamic stages.

The first stage was the formation of the third terrace. The valley incision, unloading of jointed rock mass, tectonic movement, and climatic change intensified the rock weathering. The landslide deposit started to form. The strong intermittent crustal uplift was the main tectonic movement. The second stage was a largest-scale bedrock landslide formed by early strong bending and toppling deformation of rock masses. With the coming of glacial period, the bending and toppling rock mass near the ground surface increasingly disintegrated and became to move to the river valley. Fracture surface of bending and toppling rock mass was formed. With 


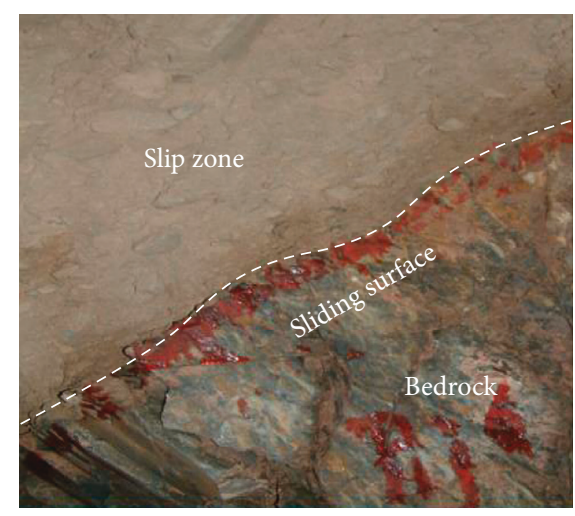

(a)

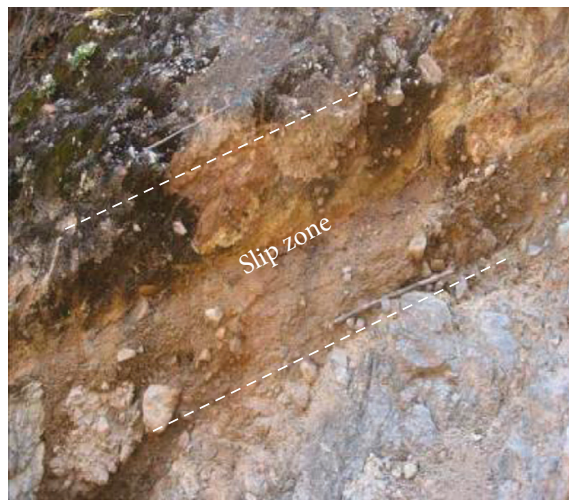

(c)

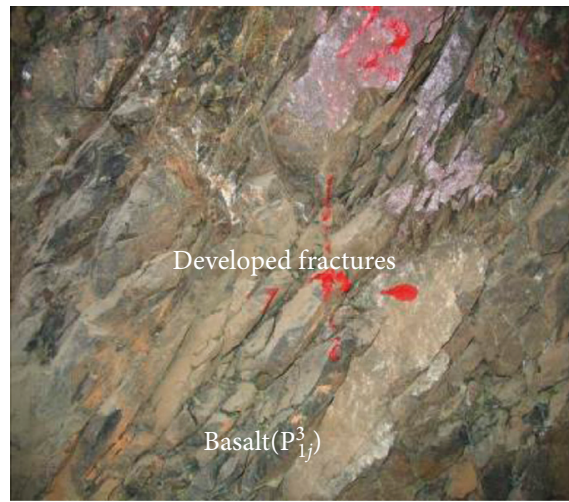

(e)

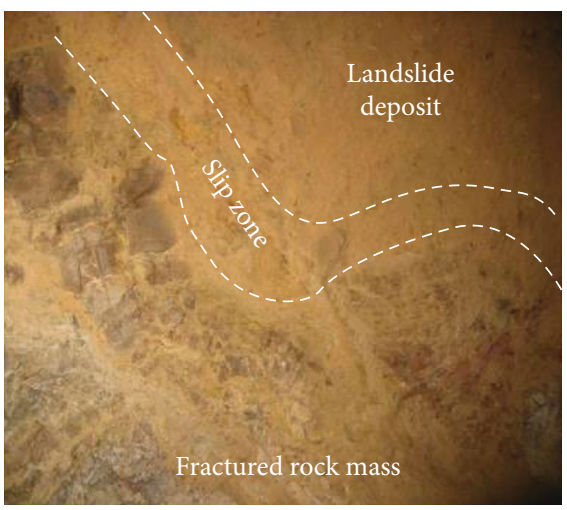

(b)

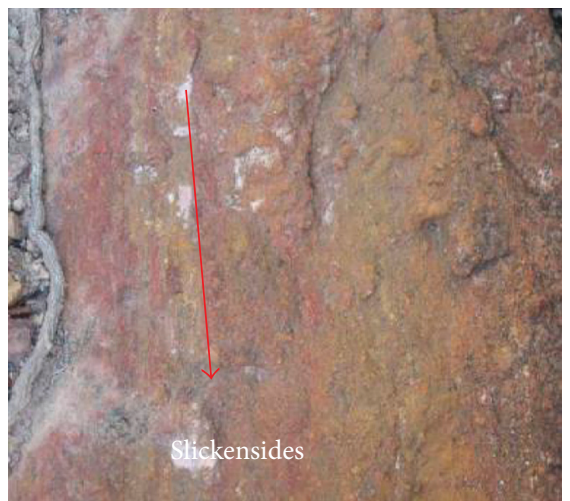

(d)

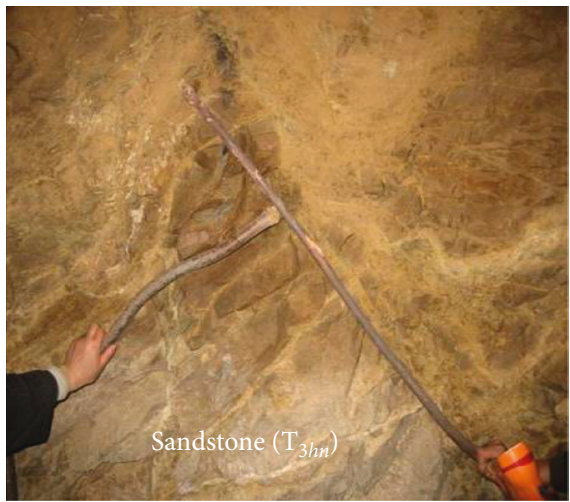

(f)

FIgURE 6: Slip zones and bedrocks.

the regression of glacial period, rock fragments were transported by glacial meltwater and covered on the third terrace. The third stage was the late reformation of the old landslide. The rock mass was more fragmented by physical geology and formed landslide deposit. The landslide deposit lost stability many times because of long-term rainfall, snowfall, artificial irrigation, groundwater fluctuation, and earthquake and thus formed the current 2 nd and 3rd landslides. The geology survey shows that the second stage landslide in Zone I has an elevation ranging from $2200 \mathrm{~m}$ to $2650 \mathrm{~m}$. The main scarp of the second stage landslide is distributed between the elevation of $2650 \mathrm{~m}$ and $2770 \mathrm{~m}$. The gradient of the main scarp is $42^{\circ}$. A platform is formed near the elevation of $2800 \mathrm{~m}$, where the average slope of ground surface is $11^{\circ}$. The third stage landslide in Zone I has an elevation ranging from $2200 \mathrm{~m}$ to $2560 \mathrm{~m}$. An arc-shaped crack with $620 \mathrm{~m}$ in length is formed near the elevation of $2500 \mathrm{~m}$. A platform is also formed in the elevation of 2480-2610 m, where the average slope of ground surface is $33^{\circ}$. The third stage landslide with a depth of 35-45 $\mathrm{m}$ in Zone I has an area of $25 \times 10^{4} \mathrm{~m}^{2}$ and a volume of $760 \times 10^{4} \mathrm{~m}^{3}$. The second stage landslide in Zone II has an elevation ranging from $2200 \mathrm{~m}$ to $2910 \mathrm{~m}$. A crack with $800 \mathrm{~m}$ in length and $20-100 \mathrm{~mm}$ in width is formed near the elevation of $2900 \mathrm{~m}$. The maximum elevation difference of the scarp is about $6 \mathrm{~m}$. Two tension-down zones in sizes of $50 \mathrm{~m} \times 4.0 \mathrm{~m} \times 0.5 \mathrm{~m}$ and $20 \mathrm{~m} \times 2.5 \mathrm{~m} \times 1.2 \mathrm{~m}$ are formed. The second stage landslide 


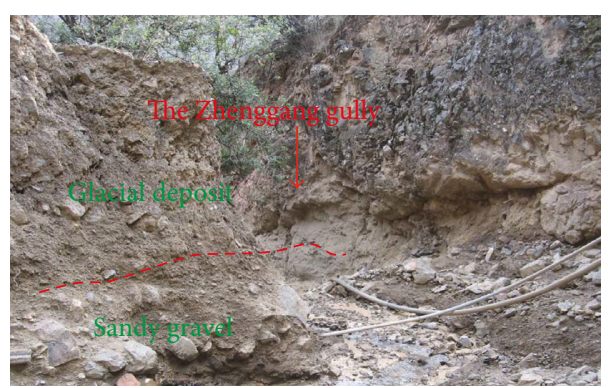

(a)

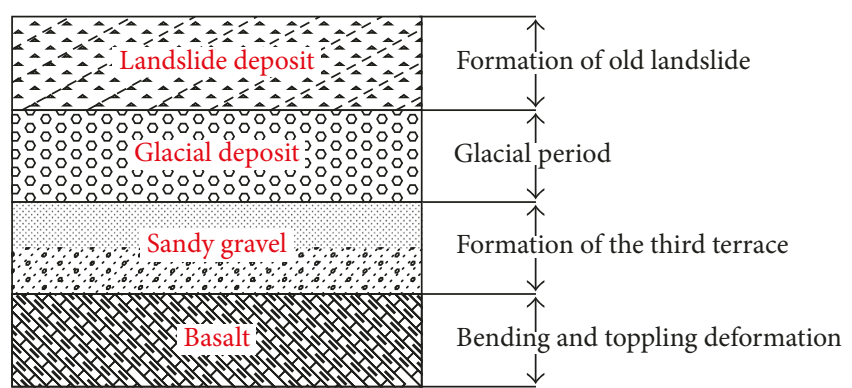

(b)

FIGURE 7: The stratigraphic contact relationship of the Zhenggang area.

with a depth of $20-85 \mathrm{~m}$ in Zone II has an area of $80 \times 10^{4} \mathrm{~m}^{2}$ and a volume of $2580 \times 10^{4} \mathrm{~m}^{3}$. The third stage landslide in Zone II has an elevation ranging from $2200 \mathrm{~m}$ to $2790 \mathrm{~m}$. Two platforms are formed in the elevation of $2720-2790 \mathrm{~m}$ and $2470-2560 \mathrm{~m}$. The average slope of ground surface is $13^{\circ}$ in the elevation of $2720-2790 \mathrm{~m}$, and the other one is $20^{\circ}$. The third stage landslide with a depth of $20-85 \mathrm{~m}$ in Zone II has an area of $60 \times 10^{4} \mathrm{~m}^{2}$ and a volume of $2070 \times 10^{4} \mathrm{~m}^{3}$.

As a whole, the whole landslide can be divided into two independent subdomains (Zone I and Zone II) due to the deep gully erosion. The slip zone disclosed by boreholes and exploratory adits is along the contact between colluvium and bedrock. The gradient of the bottom-sliding surface at the top part of Zone I is lower than that at the toe part. The main deformation direction of the landslide deposit slightly sliding to the Zhenggang gully is towards the Lancang River. The collapse of the landslide deposit at the toe part of the Zone I is serious, as shown in Figure 8. So the distribution of the activity of Zone I shall be a retrogressive landslide. The gradient of the bottom-sliding surface at the top part of Zone II is much steeper than the middle and toe parts. The deformation of the landslide deposit at the top part of Zone II is more prominent than the other parts where local deformation also appears. So the whole landslide deposit in Zone II currently is in a state of slow creep. The distribution of the activity of Zone II shall be an advancing landslide. The latest reactivations of the Zhenggang landslide occurred in October 2008 and February 2009. The former was induced by an unexpected long-term intensive rainfall (three days and three nights, the maximum rainfall amount is $78 \mathrm{~mm}$ per day), and the latter was triggered by a heavy disastrous snowfall. Both of these incidents caused pore water pressures overlying the sliding surface ranging from $1 \mathrm{~m}$ to $9 \mathrm{~m}$. Both of Zone I and Zone II appeared new signs of losing stability. More new tensional cracks appeared on the upper and middle part of the ground surface. In Figures 9(a), 9(b), and 9(e), the main scarp is much more visible; in Figure 9(f), the flanks adjacent to the sides of the sliding surface are more developed, and the bulging deformation accompanied by radial cracks distributed like a sector was more seriously near the toe of the sliding surface. The deep-seated movements along the preexisting sliding surface exposed at geological adits were clearly visible. The outward-dipping deformations and breaks of wood used for adit support were more prominent, as shown in Figures 9(c), 9(d), and 9(h). The collapse of the landslide deposit at the toe part is more serious and exposes the toe of bottom-sliding surface clearly. All evidence at that time indicated that the landslide was more likely to be reactivated again. Fortunately, such pore water pressures were dissipated effectively by some preimplemented drainage measures, for example, drainage holes. The landslide therefore got stabilized again but with a very slow creeping deformation along the slip zone.

\section{Stability Analysis of the Zhenggang Landslide}

Limit equilibrium for rigid body analysis and numerical simulation are the most popular approaches for landslide stability assessment $[5,6,18]$. However, the limit equilibrium for rigid body analysis provides no information regarding the magnitudes of the strains within the slope, nor any indication about how the strains may vary along the sliding surface, so that the progressive failure of the slope along the full length of the sliding surface cannot be known. The assumed inclinations of the side forces between slices result in the degree of computational accuracy not as high as the methods that satisfy all conditions of equilibrium so that the calculated safety factor of a slope may be less than 1.0 , but the slope is actually stable. In contrast, although the numerical simulation can not only give the stress-strain state of the slope but also reflect the process of progressive failure of the slope, the calculation of safety factor is an inevitable weakness. Therefore, how to give consideration to both two aspects shall be more convincing and more comprehensive.

3.1. Calculation Method for Safety Factor. In this study, a method employing the same definition of safety factor ( $\mathrm{SF}=$ shear strength of soil/shear stress required for equilibrium) but combining the limit equilibrium and finite element analysis together will be used for landslide stability analysis. The main idea of this method in two-dimensional domain is (a) to divide a sliding surface into short line segments according to the intersection of all finite elements and the sliding surface first; (b) to link all those line segments in turn as the calculating sliding surface; and (c) to calculate the resistance and sliding forces along the sliding surface through integrating the forces along each short line segment by the way of the length of the line segment times the stress-tensor component of each line segment's midpoint (Figure 10). The safety factor for a landslide can thus be expressed as follows: 


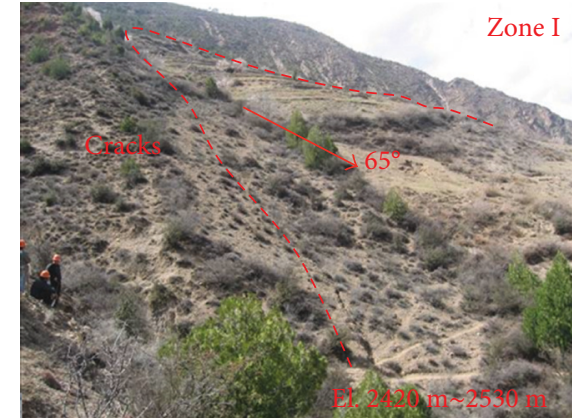

(a)

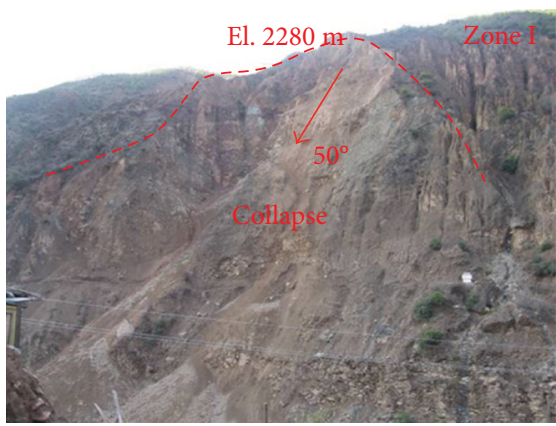

(c)

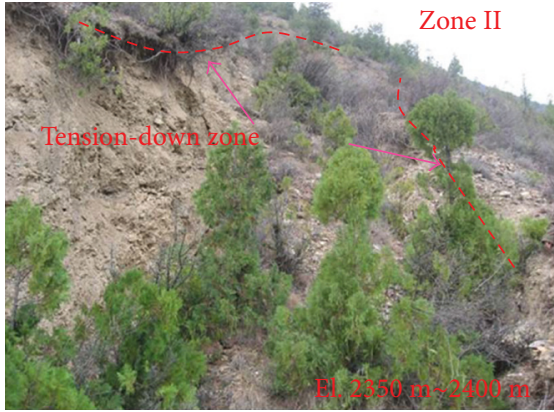

(e)

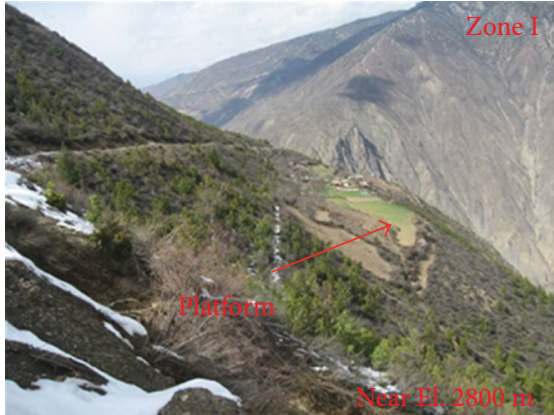

(b)

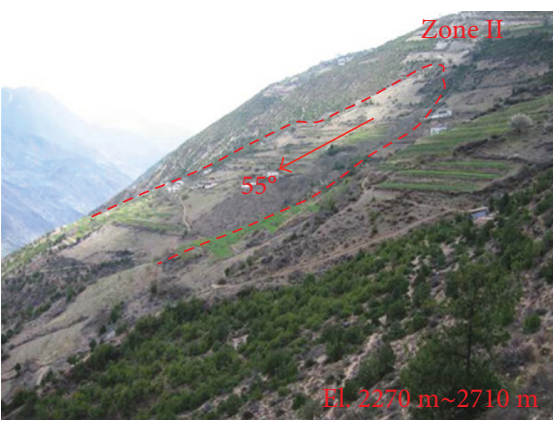

(d)

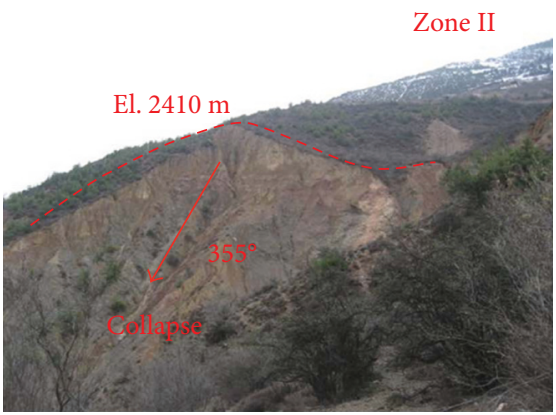

(f)

FIgURE 8: Deformation features of the Zhenggang landslide.

$$
F_{s}=\frac{\int_{L} \tau_{f} d l}{\int_{L} \tau_{\alpha} d l}=\frac{\sum_{k=1}^{n} \tau_{f}^{k} \Delta L_{k}}{\sum_{k=1}^{n} \tau_{\alpha}^{k} \Delta L_{k}},
$$

where $L$ is the whole path of the sliding surface; $\tau_{f}$ is the shear strength of soil mass; $\sigma_{\alpha}$ and $\tau_{\alpha}$ are the normal and shear stresses on an oblique plane of one soil element, respectively; $\Delta L_{k}$ is the length of the $k$ th line segment; $n$ is the total number of line segments; and $m$ is the total number of intersections between all elements and the sliding surface.

If a landslide fails towards the right (taking the counterclockwise direction to be positive), the included angle of the sliding surface and the $x$-axis should be always an obtuse angle $\alpha$, as shown in Figure 11. Taking a coordinate rotation on the original stress tensor of the midpoint of each line segment on the sliding surface, the normal and shear stresses on one plane through the midpoint of each line segment (the stress point) and the orientation of line segment can be expressed as follows:

$$
\begin{aligned}
& \sigma_{\alpha}=\frac{\left(\sigma_{x}+\sigma_{y}\right)}{2}+\frac{\left(\sigma_{x}-\sigma_{y}\right) \cos (2 \alpha-\pi)}{2}-\tau_{x y} \sin (2 \alpha-\pi) \\
& \tau_{\alpha}=\frac{\left(\sigma_{x}-\sigma_{y}\right) \cos (2 \alpha-\pi)}{2}-\tau_{x y} \sin (2 \alpha-\pi)
\end{aligned}
$$

where $\sigma_{\alpha}$ and $\tau_{\alpha}$ are the normal and shear stresses on one plane through the stress point; $\sigma_{x}, \sigma_{y}$, and $\tau_{x y}$ are the normal and shear stresses of the stress point; and $\alpha$ is the orientation of the plane through the stress point.

If the pore water pressure at the stress point is $p$, the effective shear strength, $\tau_{f}$, should be

$$
\tau_{f}=c^{\prime}+\left(\sigma_{\alpha}-p\right) \tan \phi^{\prime}
$$

where $c$ is the effective cohesion of the soil and $\varphi$ is the effective friction angle. 


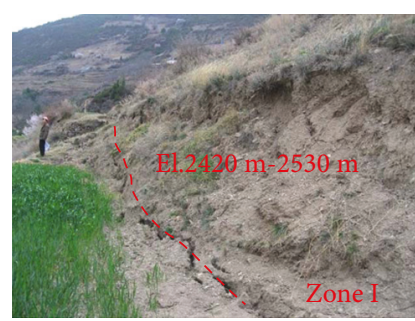

(a)

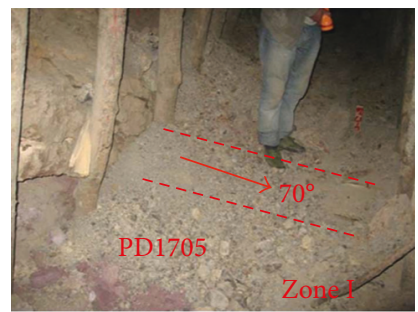

(d)

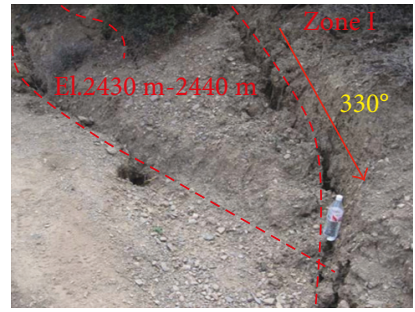

(b)

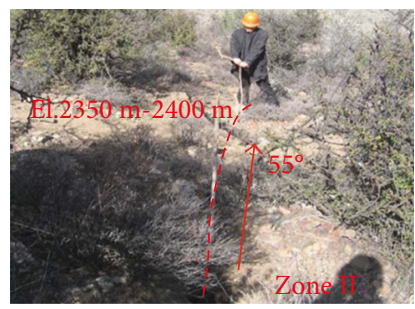

(e)

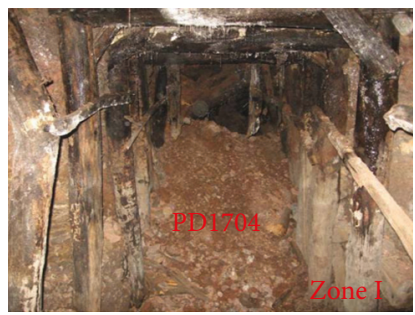

(c)

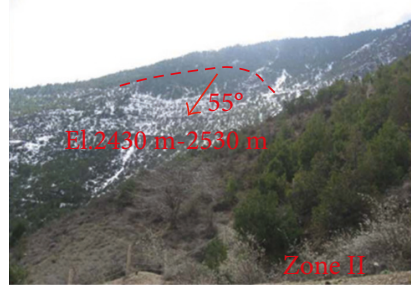

(f)

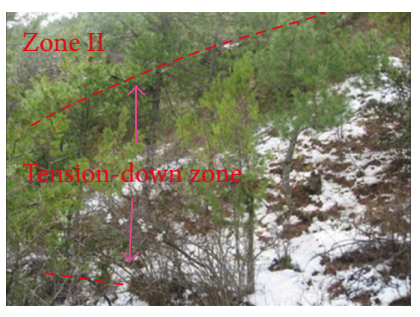

(g)

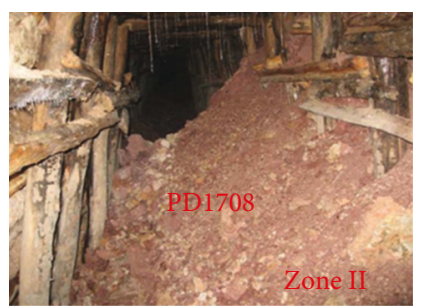

(h)

FIGURE 9: Warning signs appeared at the ground surface and exploratory adits.

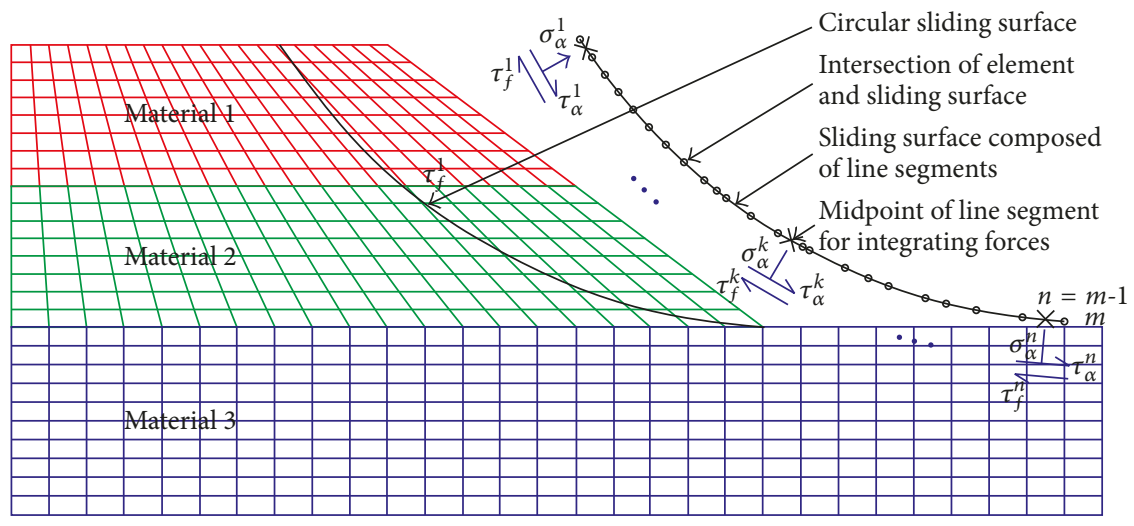

FIGURE 10: The sliding surface composed by small line segments.

Hence, the safety factor for the sliding surface composed by a series of short line segments can be

$$
\begin{aligned}
F_{s} & =\frac{\sum_{k=1}^{n} \tau_{f}^{k} \Delta L_{k}}{\sum_{k=1}^{n} \tau_{\alpha}^{k} \Delta L_{k}} \\
& =\frac{\sum_{k=1}^{n}\left[c_{k}^{\prime}+\left(\sigma_{\alpha}^{k}-p\right) \tan \phi_{k}^{\prime}\right] \Delta L_{k}}{\sum_{k=1}^{n}\left[\left(\sigma_{x}^{k}-\sigma_{y}^{k}\right) \cos 2 \alpha_{k} / 2-\tau_{x y}^{k} \sin 2 \alpha_{k}\right] \Delta L_{k}} .
\end{aligned}
$$

3.2. Calculation Model and Boundary Conditions. Since the calculation method for safety factors in this study is based on the stress state of the slope, the finite element analysis is very necessary. The finite element meshes of two-mentioned typical profiles are shown in Figure 12, where each model includes three layers and is meshed by quadrilateral elements. Considering that the landslide deposit is a kind of coarse material, the elastic-plastic properties of the landslide deposit are described by the Mohr-Coulomb model. Roller boundary conditions are applied along the model bottom and the vertical borders.

3.3. Parameter Determination. The reasonableness of shear strength of geomaterials always has a vital effect on the 


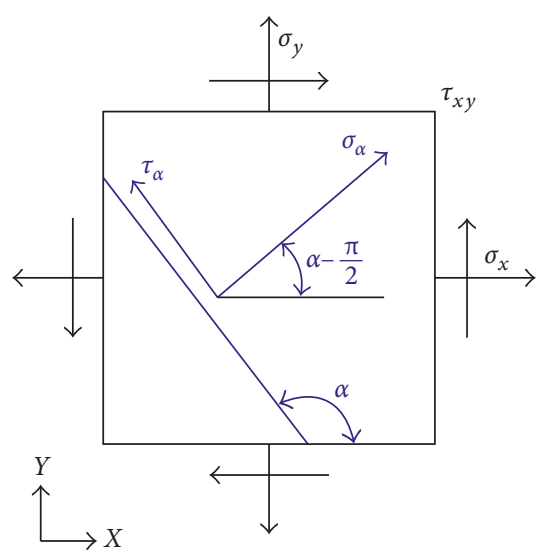

Figure 11: The normal and shear stresses on one plane through the midpoint of each line segment and the orientation of line segment.

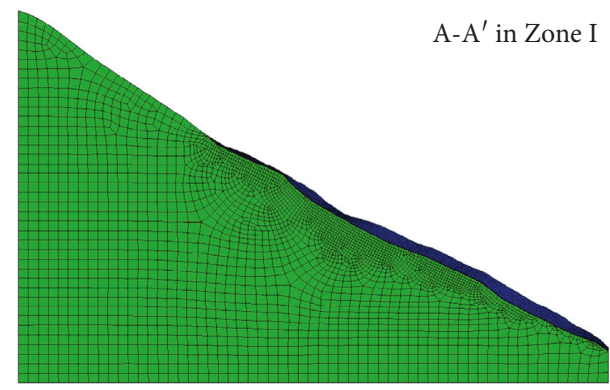

(a)

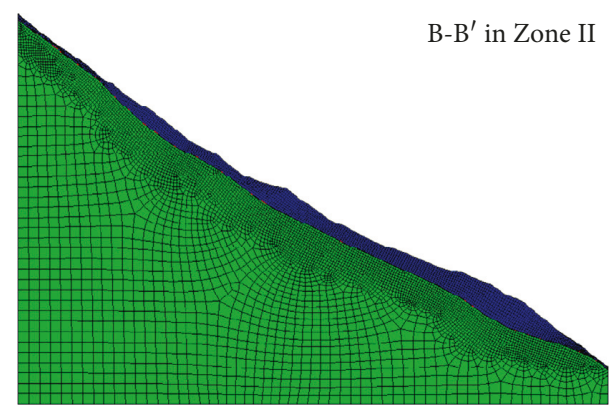

(b)

Figure 12: Finite element models of two typical cross sections.

results of landslide stability analysis, especially when the shear strength of the slip zone controls the slope stability seriously. In this study, the physical and mechanical parameters of the undisturbed slip zone clay were determined through laboratory tests, as shown in Figure 13. Due to the limits of the experimental condition and cost, the shear strength of the natural landslide deposit removing the basalt gravels in size larger than $2 \mathrm{~cm}$ was always tested as the reference value first. Then an empirical value of shear strength higher than the reference value was used for the landslide deposit. However, such shear strength could not always stand for the true strength of the landslide deposit. Back analysis is often used to ensure the proper selection of shear strength for the landslide deposit, combining with the slow creeping deformation features of the landslide

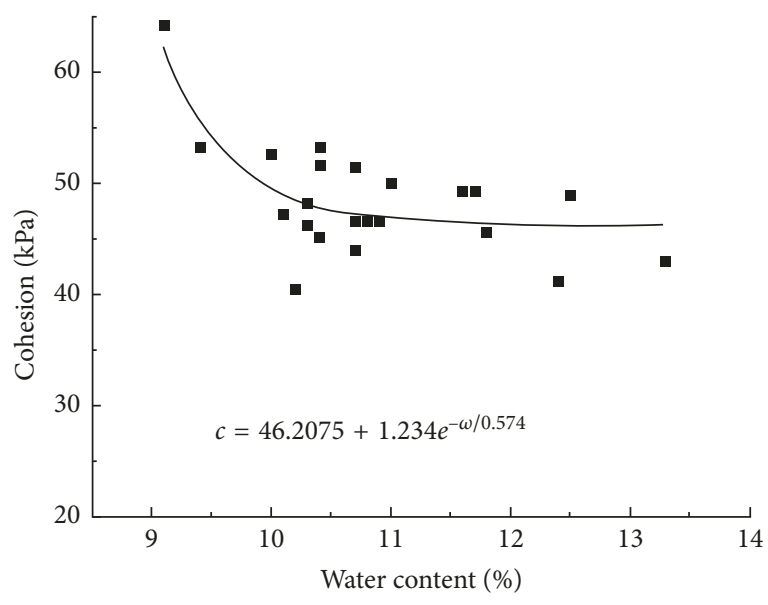

(a)

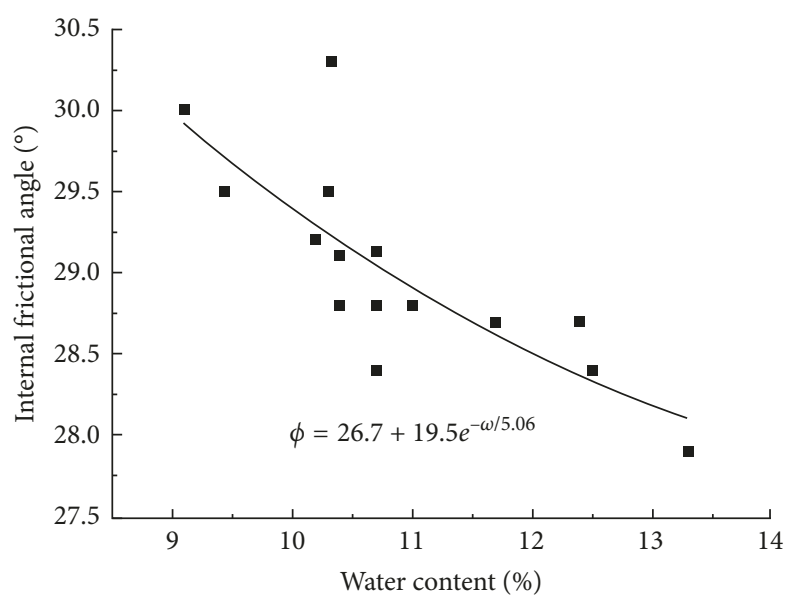

(b)

FIGURE 13: Shear strength of the slip zone clay with different water contents.

$\left(1.00<\right.$ safety factor $\left(F_{s}\right)<1.05$, minimally stable). In this study, both of these two typical cross sections were studied by back analysis taking $F_{s}=1.05$ as the level of slope stability state. Outcomes illustrated that the shear strength of the landslide deposit gained from back analysis was greater than the results of the laboratory test. So the shear strength of the landslide deposit employed the results of the back analysis. The shear strength of the bedrock was obtained from laboratory tests. So did the bulk densities, Young's modulus, and Poisson's ratio for three layers of the Zhenggang landslide deposit, as shown in Table 1.

3.4. Results of Landslide Stability Analysis. Table 2 illustrates the result of the safety factors of the Zhenggang landslide in natural and rainfall conditions. A simplification for applying pore water pressure on the sliding surface was used here for substituting the effect of rainfall conditions. The simplification is primarily attributed to the significant differences between the landslide deposit and the slip zone in structure and permeability and the simplicities of calculation. The higher permeability of the landslide deposit and the compacted structure of the slip 
TABLE 1: Recommended shear parameters of three layers for Zhenggang landslide.

\begin{tabular}{|c|c|c|c|c|c|c|c|c|c|}
\hline \multirow{2}{*}{ Methods } & & \multirow{2}{*}{$E(\mathrm{GPa})$} & \multirow{2}{*}{$v$} & \multicolumn{3}{|c|}{ Natural state } & \multicolumn{3}{|c|}{ Saturation state } \\
\hline & & & & $\rho\left(\mathrm{kg} / \mathrm{m}^{3}\right)$ & $\varphi\left({ }^{\circ}\right)$ & $c(\mathrm{kPa})$ & $\rho\left(\mathrm{kg} / \mathrm{m}^{3}\right)$ & $\varphi\left(^{\circ}\right)$ & $c(\mathrm{kPa})$ \\
\hline \multirow{3}{*}{ Laboratory tests } & Deposits & 0.10 & 0.32 & 2100 & - & - & - & - & - \\
\hline & Slip zone & 0.05 & 0.35 & - & - & - & 2050 & 26.5 & 48.0 \\
\hline & Bedrocks & 5.00 & 0.30 & 2400 & 40.0 & 250.0 & - & - & - \\
\hline Back analysis & Deposits & - & - & - & 34.0 & 50.0 & - & - & - \\
\hline
\end{tabular}

TABLE 2: Safety factors of the Zhenggang landslide deposit in natural and rainfall conditions.

\begin{tabular}{|c|c|c|c|c|c|c|c|}
\hline \multirow{2}{*}{ Methods } & \multirow{2}{*}{ Conditions } & \multicolumn{3}{|c|}{ Stages of $\mathrm{A}-\mathrm{A}^{\prime}$ in Zone I } & \multicolumn{3}{|c|}{ Stages of B-B' in Zone II } \\
\hline & & 1 st & 2nd & $3 r d$ & 1 st & 2nd & $3 r d$ \\
\hline Limit equilibrium for rigid body analysis & Natural & 1.130 & 1.139 & 1.125 & 1.083 & 1.172 & 1.236 \\
\hline & Natural & 1.176 & 1.147 & 1.130 & 1.098 & 1.190 & 1.248 \\
\hline The method in this study & Rainfall & 1.121 & 1.098 & 1.074 & 1.070 & 1.161 & 1.215 \\
\hline
\end{tabular}

TABLE 3: Factors of safety for different landslide stages in Zone I and Zone II.

\begin{tabular}{|c|c|c|c|c|c|c|c|c|}
\hline \multirow{2}{*}{ Sliding surfaces } & \multirow{2}{*}{$\varphi\left({ }^{\circ}\right)$} & \multicolumn{7}{|c|}{$c(\mathrm{kPa})$} \\
\hline & & 33.60 & 40.80 & 45.60 & 48.00 & 50.40 & 55.20 & 62.40 \\
\hline \multirow{7}{*}{ The 3rd stage of $\mathrm{A}-\mathrm{A}^{\prime}$ in Zone I } & 18.55 & 0.807 & 0.819 & 0.827 & 0.831 & 0.835 & 0.843 & 0.855 \\
\hline & 22.53 & 0.952 & 0.964 & 0.972 & 0.976 & 0.980 & 0.988 & 1.000 \\
\hline & 25.18 & 1.054 & 1.066 & 1.074 & 1.078 & 1.082 & 1.090 & 1.102 \\
\hline & 26.50 & 1.106 & 1.118 & 1.126 & 1.130 & 1.134 & 1.142 & 1.154 \\
\hline & 27.83 & 1.160 & 1.172 & 1.180 & 1.184 & 1.188 & 1.196 & 1.207 \\
\hline & 30.48 & 1.271 & 1.283 & 1.291 & 1.295 & 1.299 & 1.307 & 1.319 \\
\hline & 34.45 & 1.450 & 1.462 & 1.470 & 1.474 & 1.478 & 1.485 & 1.497 \\
\hline \multirow{7}{*}{ The 1st stage of $\mathrm{B}-\mathrm{B}^{\prime}$ in Zone II } & 18.55 & 0.850 & 0.855 & 0.858 & 0.860 & 0.861 & 0.865 & 0.870 \\
\hline & 22.53 & 0.965 & 0.970 & 0.974 & 0.976 & 0.977 & 0.981 & 0.986 \\
\hline & 25.18 & 1.046 & 1.051 & 1.055 & 1.056 & 1.058 & 1.062 & 1.067 \\
\hline & 26.50 & 1.088 & 1.093 & 1.096 & 1.098 & 1.100 & 1.103 & 1.108 \\
\hline & 27.83 & 1.130 & 1.136 & 1.139 & 1.141 & 1.143 & 1.146 & 1.151 \\
\hline & 30.48 & 1.219 & 1.224 & 1.228 & 1.229 & 1.231 & 1.235 & 1.240 \\
\hline & 34.45 & 1.361 & 1.367 & 1.370 & 1.372 & 1.373 & 1.377 & 1.382 \\
\hline
\end{tabular}

zone always lead to a higher pore water pressure overlying the sliding surface rapidly, which actually results in gradual destabilization of the landslides. In this study, we adopt a water pressure of $3 \mathrm{~m}$ on the sliding surface for rainfall conditions. This value is based on the real condition of the project and the suggestion of engineers. The distributions of pore water pressures along the sliding surface are assumed to be proportional to the depth of the sliding surface. Outcomes show that both the results of the limit equilibrium for rigid body analysis and the proposed method are in good consistence with each other. The safety factors of all stages of the landslide larger than 1.05 indicate that the landslide in both natural and rainfall conditions is in a basically stable state $\left(1.05<F_{s}<F_{\text {st }}\right.$, where $F_{\text {st }}$ is a safety factor threshold of the landslide under different conditions, decided by the specification). The safety factors of the third stage in Zone I and the first stage in Zone II having the lowest values in rainfall state demonstrate that the landslide deposit may have an evident probability of instability when there are pore water pressures existing on the sliding surfaces. Therefore, it is necessary to enhance the deformation monitoring of the landslide in rainy season.

The main purpose of sensitivity analysis is to determine which controlling parameters have greater influences on landslide stability. In this study, the sliding surfaces of the third stage in Zone I and the first stage in Zone II are selected for calculating safety factors with different shear parameter combinations. Results in Table 3 and Figure 14 show that when the internal frictional angle of the slip zone increases one degree, the safety factor increases by 0.0404 for the third stage in Zone I but by 0.0321 for the first stage in Zone II. When the cohesion of the slip zone increases $1 \mathrm{kPa}$, the safety factor increases by 0.0017 for the third stage in Zone I but by 0.0007 for the first stage in Zone II. The average sensitivity coefficient of the internal frictional angle $3.63 \%$ is 30.25 times the effect of the cohesion $0.12 \%$. Therefore, the internal frictional angle of the slip zone has a much greater influence on landslide stability.

Pore water pressure induced by rainfalls is always the main culprit of landslide failure. Melting water and atmospheric precipitation infiltrating into the landslide deposit rapidly, on the one hand, causes an obvious increase in the soil moisture content, resulting in an evident reduction of the shear strength of the soil; on the other hand, they increase soil unit weight and pore water pressure leading to an increase in the driving forces but a decrease in the resisting forces on a landslide so as to aggravate landslide deformation 


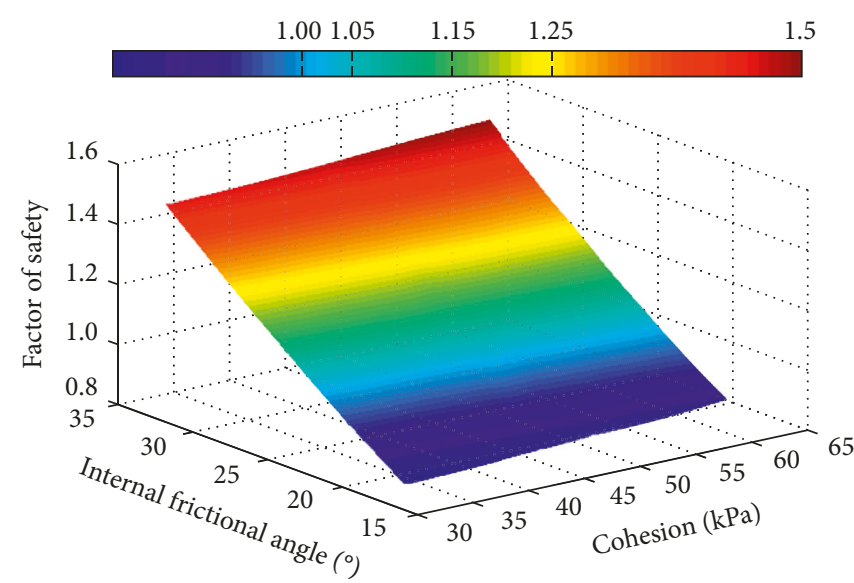

(a)

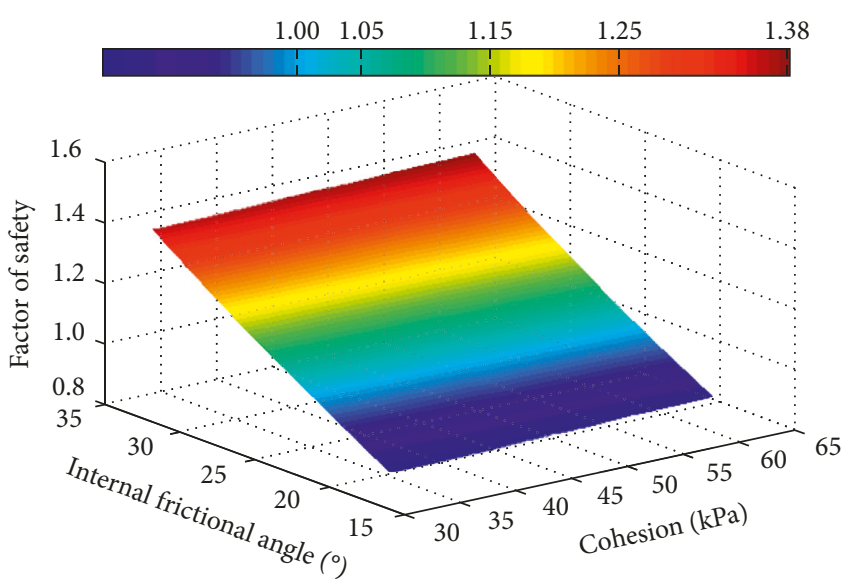

(b)

FIGURE 14: Safety factors under different shear strength: (a) the 3rd in Zone I; (b) the 1st in Zone II.

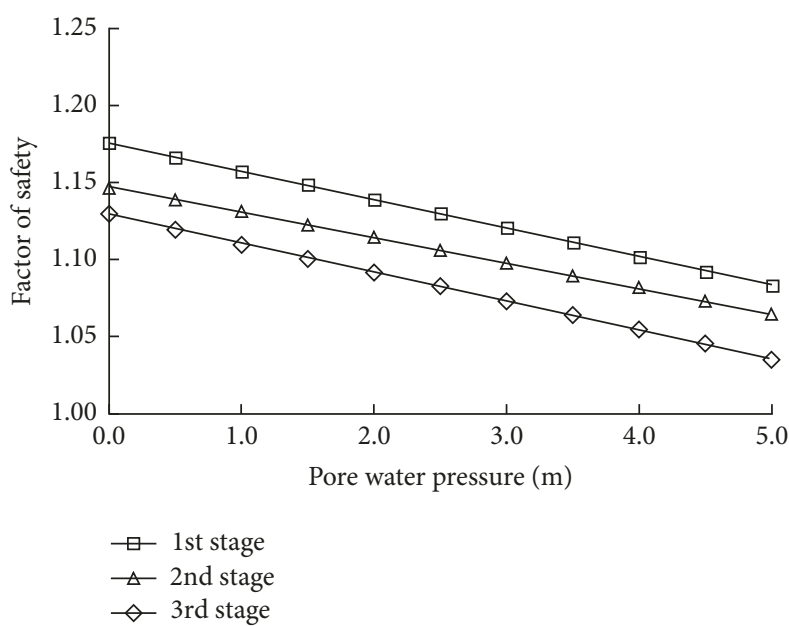

(a)

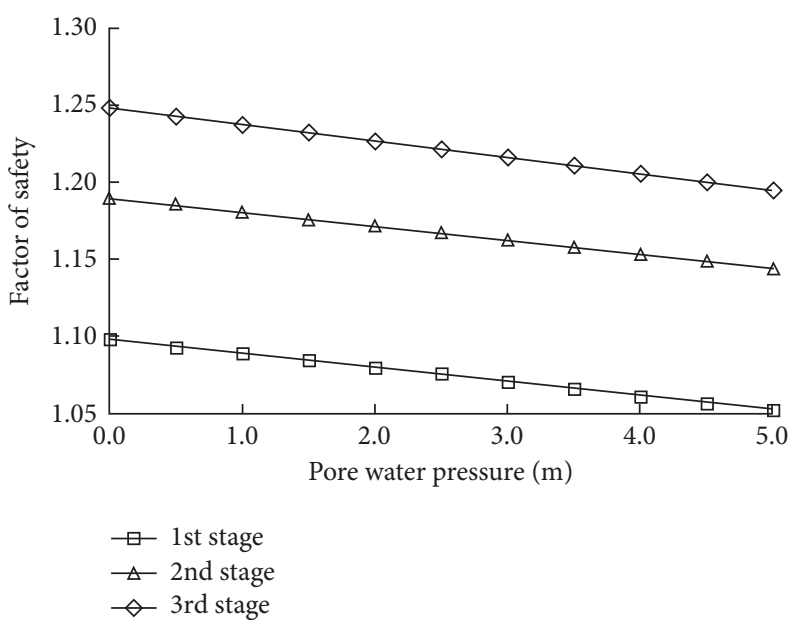

(b)

FiguRE 15: Safety factors for landslides under different pore water pressures.

and finally give rise to a destabilization of the landslide. Figure 15 shows that the safety factors of landslides decrease quickly with the increase of the pore water pressure. When the pore water pressure reaches $5 \mathrm{~m}$, the third stage in Zone I loses stability in advance.

\section{Analysis on Failure Mechanism of the Zhenggang Landslide}

4.1. Calculation Model and Boundary Conditions. In order to interpret the deformation mode and failure mechanism of the Zhenggang landslide, a three dimensional mesh model was employed. The model is $1900 \mathrm{~m} \times 1230 \mathrm{~m} \times 1855 \mathrm{~m}$ in dimensions and composed of 8080 triangular prism elements, as shown in Figure 16. The Mohr-Coulomb model is applied to describe the elastic-plastic properties of the materials. Roller boundary conditions are applied along the model bottom and the vertical borders.
4.2. Landslide Failure Mechanism Analysis. Figure 17 shows that the plastic zones of the landslide deposit in natural state are mainly distributed along the downstream boundary of the landslide and the Zhenggang gully. The plastic zones of the slip zone are interconnected locally. So the whole landslide is in a basically stable state in the natural state. The plastic zones more obvious at the upper part of Zone II than the other parts illustrate that the large deformation occurs, which is in keeping with the actual situation of the engineering.

Since the rainfall infiltration, resulting in high pore water pressure on the sliding surface, is the most significant external triggering factor for the failure of the Zhenggang landslide, the water pressure of $3 \mathrm{~m}$ on the sliding surface is implemented for substituting the effect of rainfall conditions. The water pressures on the sliding surface are also assumed to be proportional to the depth of the sliding surface, as shown in Figure 18. Figure 19 shows that the middle-lower part of Zone I and the upper part of Zone II have the most serious plastic deformations under rainfall 


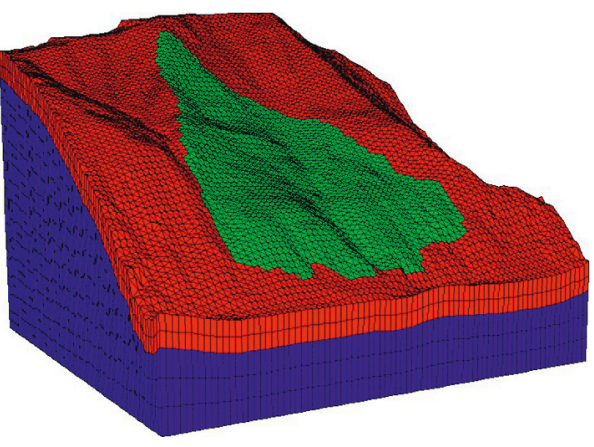

FIGURE 16: 3D finite element model for the Zhenggang landslide.

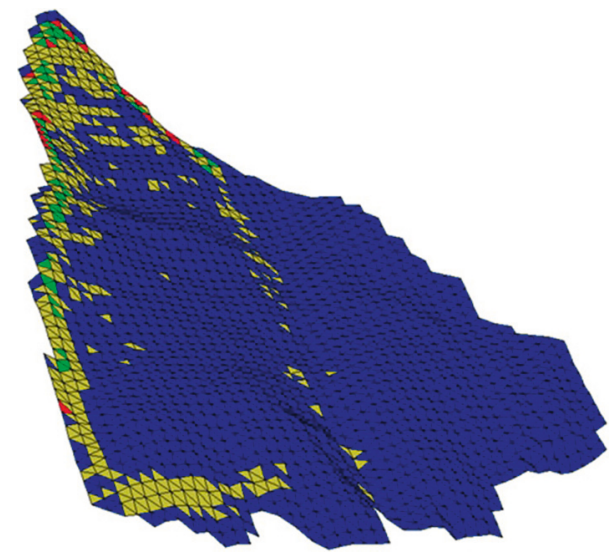

(a)

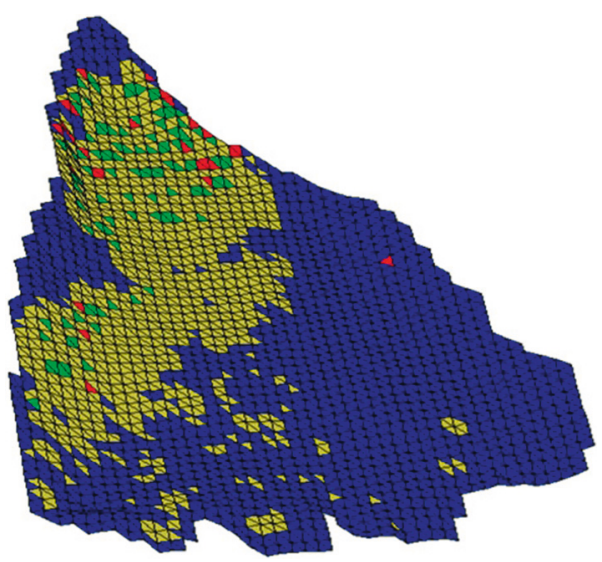

(b)

Figure 17: The plastic zones of the landslide deposit (a) and the slip zone (b) in natural condition.

conditions. The third stage of Zone I has the highest potential of the instability and may disintegrate ahead. So the distribution of the activity of Zone I should be a retrogressive landslide. The plastic zones at the upper part of Zone II are more than the other parts, which implies that there is more serious deformation occurring at the upper part of Zone II. So the distribution of the activity of Zone II is more likely to be an advancing landslide. The plastic zones of the slip zone are almost interconnected in Figure 19(b), which indicates that the whole landslide may lose stability with the water

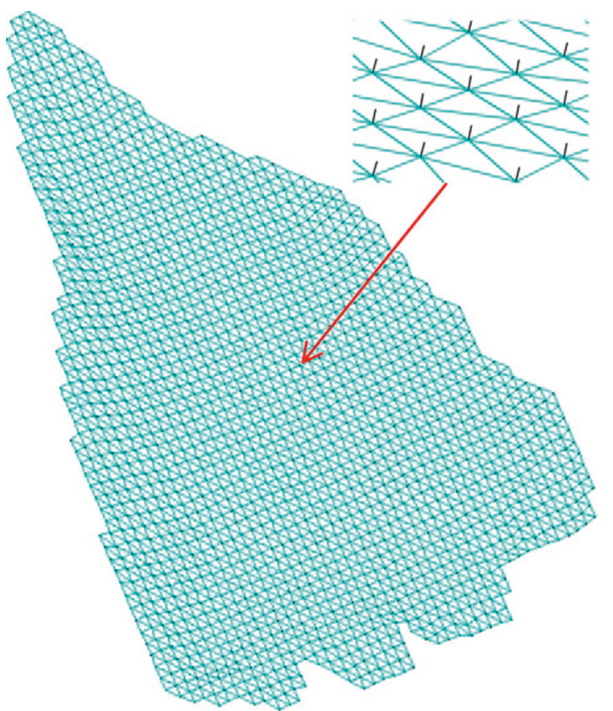

FIgURE 18: The design sketch of pore water pressures.

pressure of $3 \mathrm{~m}$ on the sliding surface. Compared with the plastic zones of the slip zone in Figure 17(b) with that in Figure 19(b), it can be inferred that higher pore water pressure has a significant influence on the landslide stability. The third stage of Zone I is much more sensitive to the pore water pressure than other landslides and may lose stability earlier than other landslides. So the landslide in Zone I has a higher risk than that in Zone II during or after rainfalls. Effective drainage measures are therefore beneficial for improving the safety of the landslide deposit. Figure 20 shows that the deformations at the lower part of Zone I and the upper part of Zone II are the most remarkable, which actually proves the foregoing conclusions again.

\section{Comprehensive Treatment Scheme}

Since the Zhenggang landslide has a serious impact on the safety of the dam, three treatment schemes taking both engineering safety and cost into consideration have been proposed by designers. The first treatment scheme mainly focuses on conventional slope control measures, such as slope cutting, anchorage, and slope drainage. The second treatment scheme is to reserve exits for diversion tunnels, tailrace tunnels, and emptying tunnels at the upstream of the Zhenggang landslide first and then use three underground drainage tunnels to bring water to the downstream of the Zhenggang landslide. And the third treatment scheme is to set all exits for diversion tunnels, flood discharge tunnel, tailrace tunnels, and emptying tunnels at the downstream of the Zhenggang landslide. Because both the second and third treatment schemes have the same influence on the stability of the landslide deposit, only the first and third treatment schemes will be discussed in this study. Table 4 shows the detailed treatment designing for landslide stabilization.

Results of landslide stability analysis indicate that although the stability of all landslides in both Zone I and Zone II is improved under the first scheme, the safety factors of the landslides in Zone II do not meet the requirement of 


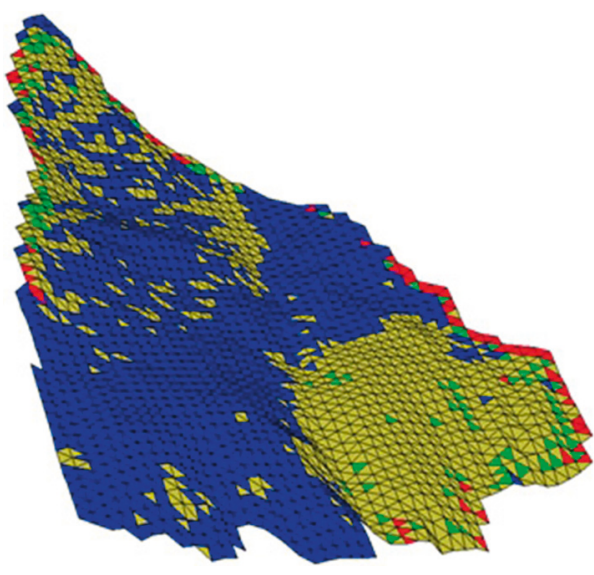

(a)

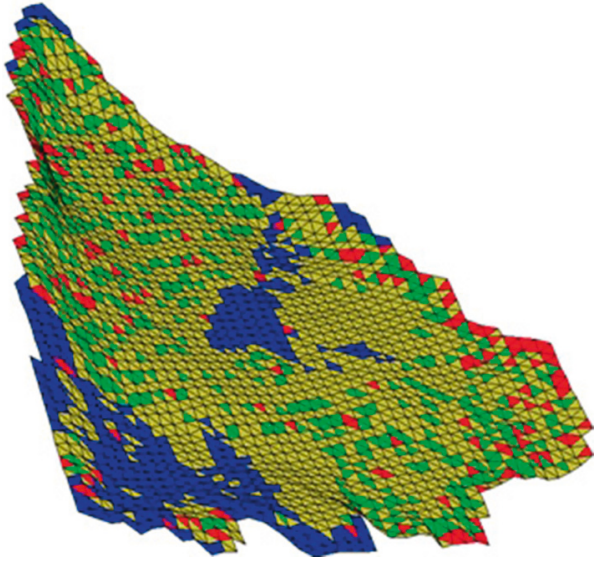

(b)

Figure 19: The plastic zones of the landslide deposit (a) and the slip zone (b) in rainfall condition.
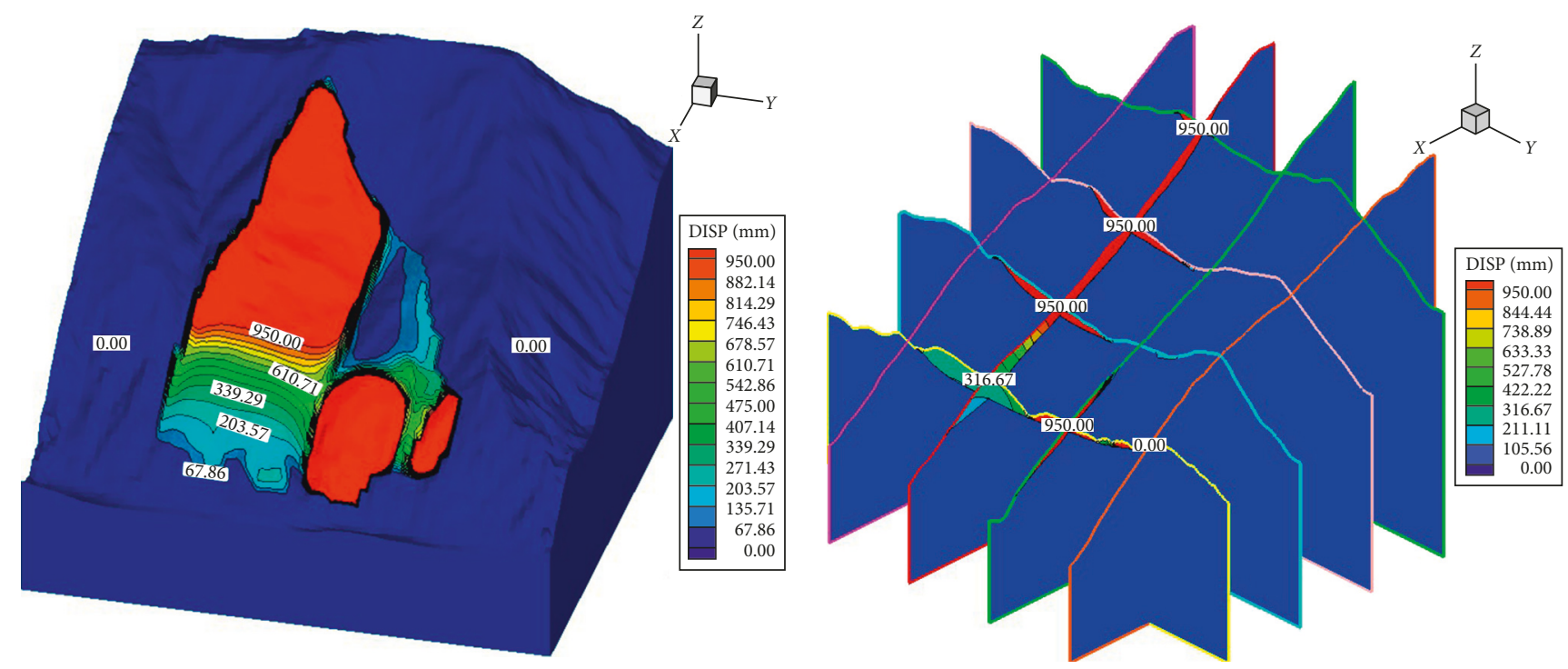

FIgURe 20: The total displacement of the whole landslide deposit.

TABLE 4: Treatment designing for landslide stabilization.

\begin{tabular}{|c|c|c|}
\hline & Zone I & Zone II \\
\hline The first scheme & $\begin{array}{l}\text { Reasons: the exits of flood discharge tunnel lie below } \\
\text { the foot of Zone I. } \\
\text { Measures: dig out all landslide deposit above the } \\
\text { strong weathered line; take slope rates of } 1: 1.6,1: 1.4 \text {, } \\
1: 1 \text { and } 1: 0.8 \text {; add prestressed anchor cable; } \\
\text { necessary slope protection and intercepting drain } \\
\text { arrangement; deformation monitoring. }\end{array}$ & $\begin{array}{l}\text { Reasons: better in stability than Zone I; a large volume } \\
\text { of the landslide; impossible to dig out all landslide } \\
\text { deposit and add supports widely in Zone II. } \\
\text { Measures: reducing load by slope cutting in elevations } \\
\text { of } 2800-3150 \mathrm{~m} \text {; applying support of antislide pile; } \\
\text { deep drainage; deformation monitoring. }\end{array}$ \\
\hline The third scheme & \multicolumn{2}{|c|}{$\begin{array}{l}\text { Reasons: even though the landslide occurs after building construction, it will not have influence on the safety of } \\
\text { reservoir operation. } \\
\text { Measures: intercepting drain; deep drainage; crack closed. }\end{array}$} \\
\hline
\end{tabular}

hydroelectric project. A landslide may occur during the process of slope cutting. So effective measures for deformation monitoring must be emphasized in the first scheme. In contrast, the stability of all landslides under the third scheme can meet the requirement of hydroelectric project after deep drainage well. Although the engineering cost of the third scheme is more than that of the first scheme, the third scheme has the minimum potential disturbance to the landslide and can reduce the difficulty of engineering construction, leading to much less risk of landslides. 
Therefore, the treatment effect of the third scheme is better than that of the first scheme.

\section{Conclusions}

The Zhenggang landslide is an ancient large-scale landslide. The geological investigation on the stratigraphic contact relationship of the Zhenggang area indicated that the formation of the landslide had experienced three stages, including the formation of the third terrace, glacial period, and the late reformation of old landslide. The deformation and failure of the sliding surface at depth show that the distribution of the activity of the landslide is a retrogressive landslide in Zone I but an advancing landslide in Zone II. The results of borehole exploration and exploratory adits demonstrated that the landslide deposit was under a metastable state and much more likely to lose stability along the weak interlayered clay during intense or prolonged rainfall infiltration. Outcomes from the numerical stability analysis and the failure mechanism of the Zhenggang landslide prove the same conclusions and indicate that the internal frictional angle of the slip zone has a much greater influence on landslide stability. Results of comparing different treatment schemes indicate that it is much better to set all exits of diversion tunnels, flood discharge tunnel, tailrace tunnels, and emptying tunnels at the downstream of the Zhenggang landslide for the dam safety, in spite of more investment.

\section{Conflicts of Interest}

The authors declare that they have no conflicts of interest.

\section{Acknowledgments}

This study was supported by the National Key R\&D Program of China (2017YFC1501100), the Natural Science Foundation of Jiangsu Province (BK20171006), and the Natural Science Foundation of China (11772118).

\section{References}

[1] T. A. Blodgett, C. Blizard, and B. L. Isacks, "Andean landslide hazards," in Geomorphological Hazards in High Mountain Areas, J. Kalvoda and C. L. Rosenfeld, Eds., pp. 211-227, Springer, Dordrecht, Netherlands, 1998.

[2] J. W. Zhou, W. Y. Xu, X. G. Yang, C. Shi, and Z. H. Yang, "The 28 October 1996 landslide and analysis of the stability of the current Hua-shiban slope at the Liangjiaren Hydropower Station, Southwest China," Engineering Geology, vol. 114, no. 1-2, pp. 45-56, 2010.

[3] Y. Zhang, W. Y. Xu, J. F. Shao, L. F. Zou, and H. K. Sun, "Comprehensive assessment and global stabilisation measures of a large landslide in hydropower engineering," European Journal of Environmental and Civil Engineering, vol. 17, no. 3, pp. 154-175, 2013.

[4] Y. Zhang, J. F. Shao, W. Y. Xu, and H. K. Sun, "Stability analysis of a large landslide in hydropower engineering," Natural Hazards, vol. 70, no. 1, pp. 527-548, 2014.

[5] Y. M. Cheng and C. K. Lau, Slope Stability Analysis and Stabilization: New Methods and Insight, CRC Press, Boca Raton, FL, USA, 2014.
[6] J. M. Duncan, "State of the art: limit equilibrium and finiteelement analysis of slopes," Journal of Geotechnical Engineering, vol. 122, no. 7, pp. 577-596, 1996.

[7] E. Hoek and J. Bray, Rock Slope Engineering, Institute of Mining and Metallurgy, London, UK, 1981.

[8] T. S. Hou, G. L. Xu, Y. J. Shen, Z. Z. Wu, N. N. Zhang, and R. Wang, "Formation mechanism and stability analysis of the Houba expansive soil landslide," Engineering Geology, vol. 161, pp. 34-43, 2013.

[9] R. Q. Huang, "Large-scale landslides and their sliding mechanisms in China since the 20th century (in Chinese)," Chinese Journal of Rock Mechanics and Engineering, vol. 26, pp. 433-454, 2007.

[10] J. F. Shroder, Landslide Hazards, Risks, and Disasters, Academic Press, Cambridge, MA, USA, 2014.

[11] S. Zhang, Q. Xu, and Z. Hu, "Effects of rainwater softening on red mudstone of deep-seated landslide, Southwest China," Engineering Geology, vol. 204, pp. 1-13, 2016.

[12] C. Padilla, Y. Onda, T. Iida, S. Takahashi, and T. Uchida, "Characterization of the groundwater response to rainfall on a hillslope with fractured bedrock by creep deformation and its implication for the generation of deep-seated landslides on Mt. Wanitsuka, Kyushu Island," Geomorphology, vol. 204, pp. 444-458, 2014.

[13] L. L. Zhang, J. Zhang, L. M. Zhang, and W. H. Tang, "Stability analysis of rainfall-induced slope failure: a review," Proceedings of the Institution of Civil Engineers-Geotechnical Engineering, vol. 164, no. 5, pp. 299-316, 2011.

[14] J. Kim, S. Jeong, and R. A. Regueiro, "Instability of partially saturated soil slopes due to alteration of rainfall pattern," Engineering Geology, vol. 147-148, pp. 28-36, 2012.

[15] A. M. Santoso, K. K. Phoon, and S. T. Quek, "Effects of soil spatial variability on rainfall induced landslides," Computers \& Structures, vol. 89, no. 11-12, pp. 893-900, 2011.

[16] G. Sorbino and M. V. Nicotera, "Unsaturated soil mechanics in rainfall-induced flow landslides," Engineering Geology, vol. 165, pp. 105-132, 2013.

[17] L. Zhang, H. M. Tang, C. R. Xiong et al., "Movement process simulation of high-speed long-distance Jiweishan landslide with PFC3D," Chinese Journal of Rock Mechanics and Engineering, vol. 31, pp. 2601-2612, 2012.

[18] J. J. Clague and D. Stead, Landslides: Types, Mechanisms and Modeling, Cambridge University Press, Cambridge, UK, 2012.

[19] W. Y. Xu, Q. Zhang, J. C. Zhang, R. B. Wang, and R. K. Wang, "Deformation and control engineering related to huge landslide on left bank of Xiluodu reservoir, south-west China," European Journal of Environmental and Civil Engineering, vol. 17, no. 1, pp. 249-268, 2013.

[20] G. Zhang, R. Wang, J. Qian, J. M. Zhang, and J. Qian, "Effect study of cracks on behavior of soil slope under rainfall conditions," Soils and Foundations, vol. 52, no. 4, pp. 634-643, 2012 . 


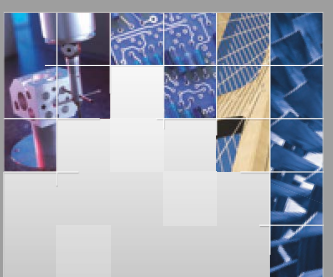

\section{Enfincering}
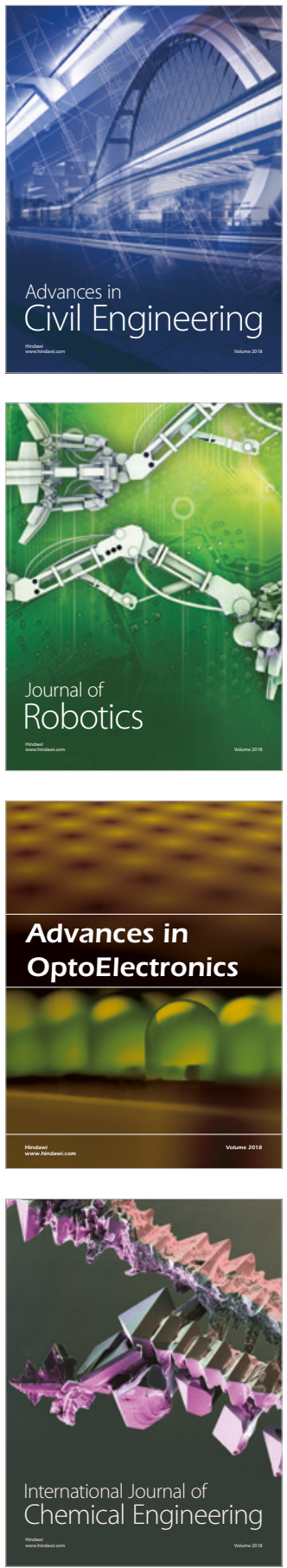

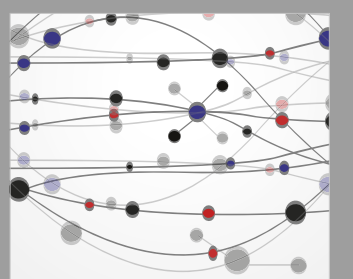

\section{Rotating \\ Machinery}

The Scientific World Journal

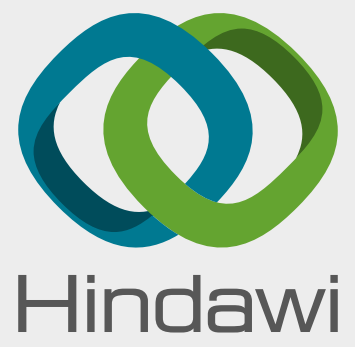

Submit your manuscripts at

www.hindawi.com
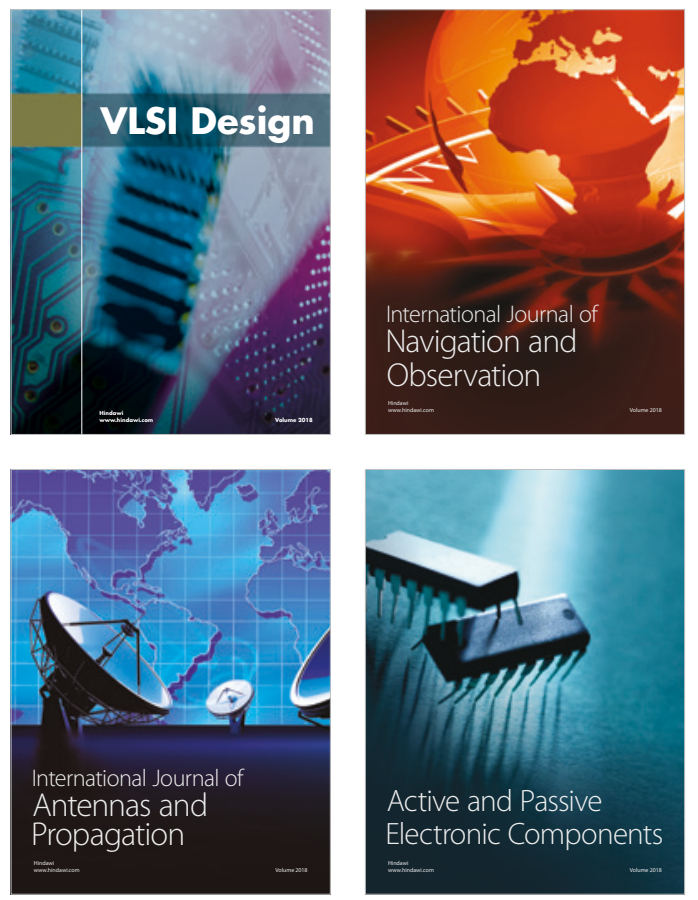
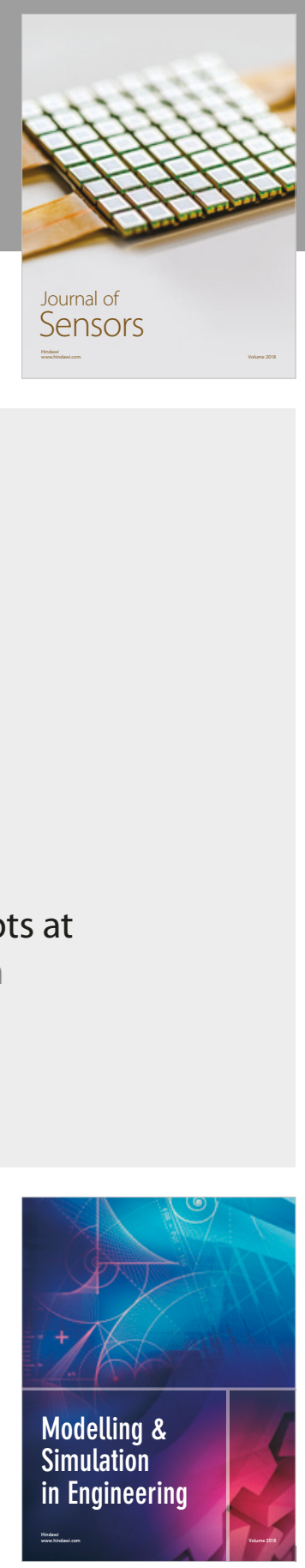

\section{Advances \\ Multimedia}
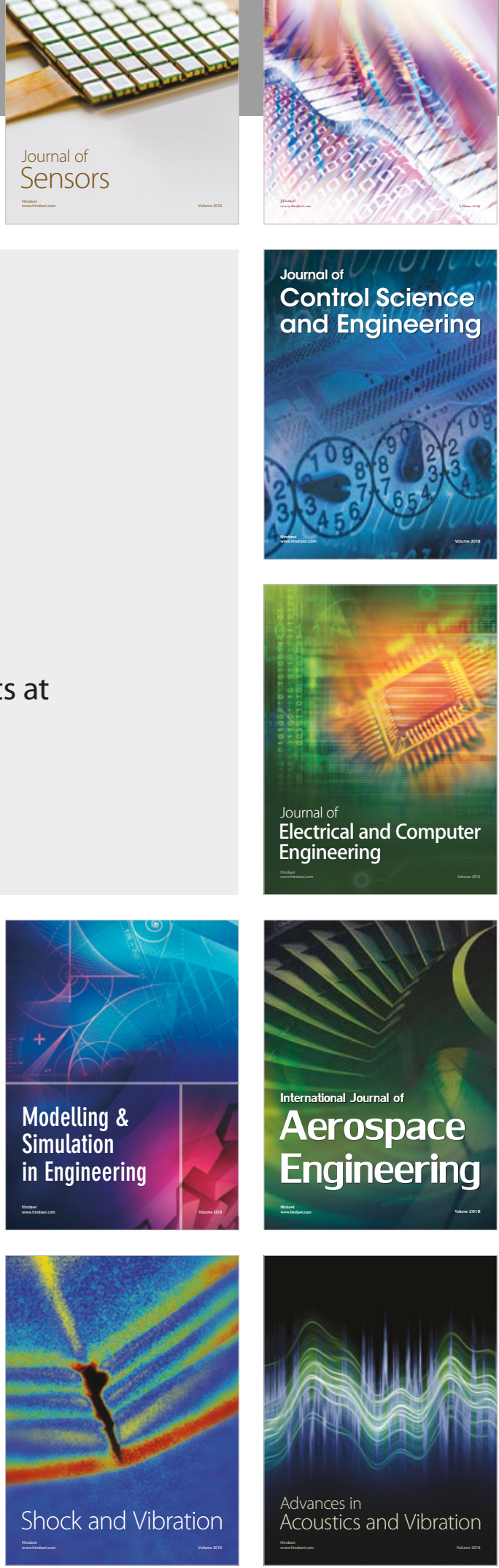